1

\title{
Linking the von Karman equations to the practical design of plates
}

\author{
by \\ Jurgen Becque \\ The University of Cambridge, Cambridge, UK
}

Abstract:

The Föppl-von Karman equations describe the highly non-linear post-buckling behaviour of elastic plates, but are notorious for their unwieldiness. Owing to the lack of a sufficiently general solution, the practical design of plates against local buckling is instead based on the empirical Winter equation. This paper aims to connect both concepts by analytically deriving a Winter-type equation, taking the Föppl-von Karman equations as a starting point. The latter are first simplified in a way which preserves the main mechanics of the post-buckling behaviour of plates and are combined with a failure criterion based on von Karman's effective width concept. The resulting equation is solved by means of a truncated Fourier series. This yields excellent predictions of the plate behaviour over an ever more extended range of post-buckling behaviour as the number of Fourier terms increases, both for geometrically perfect and imperfect plates. As a crowning result, a closed-form expression is presented as an equivalent to the empirical Winter equation. This new expression agrees closely with the Winter curve and allows an analysis of the various factors affecting the local buckling capacity of plates.

Keywords: plate, local buckling, stability, von Karman equations 
30

31

32

\section{Introduction}

The von Karman equations (sometimes referred to as the Föppl-von Karman equations) comprise a system of two coupled non-linear partial differential equations which describe the post-buckling behaviour of thin elastic plates (Föppl 1907, von Karman 1910):

$$
\mathrm{D}\left[\frac{\partial^{4} \mathrm{w}}{\partial \mathrm{x}^{4}}+2 \frac{\partial^{4} \mathrm{w}}{\partial \mathrm{x}^{2} \partial \mathrm{y}^{2}}+\frac{\partial^{4} \mathrm{w}}{\partial \mathrm{y}^{4}}\right]=\mathrm{p}_{\mathrm{z}}+\mathrm{t}\left[\frac{\partial^{2} \phi}{\partial \mathrm{y}^{2}} \frac{\partial^{2}\left(\mathrm{w}+\mathrm{w}_{0}\right)}{\partial \mathrm{x}^{2}}-2 \frac{\partial^{2} \phi}{\partial \mathrm{y} \partial \mathrm{x}} \frac{\partial^{2}\left(\mathrm{w}+\mathrm{w}_{0}\right)}{\partial \mathrm{x} \partial \mathrm{y}}+\frac{\partial^{2} \phi}{\partial \mathrm{x}^{2}} \frac{\partial^{2}\left(\mathrm{w}+\mathrm{w}_{0}\right)}{\partial \mathrm{y}^{2}}\right]
$$

$$
\frac{\partial^{4} \phi}{\partial x^{4}}+2 \frac{\partial^{4} \phi}{\partial x^{2} \partial y^{2}}+\frac{\partial^{4} \phi}{\partial y^{4}}=E\left[\left(\frac{\partial^{2} w}{\partial x \partial y}\right)^{2}-\frac{\partial^{2} w}{\partial x^{2}} \frac{\partial^{2} w}{\partial y^{2}}+2 \frac{\partial^{2} w_{0}}{\partial x \partial y} \frac{\partial^{2} w}{\partial x \partial y}-\frac{\partial^{2} w_{0}}{\partial x^{2}} \frac{\partial^{2} w}{\partial y^{2}}-\frac{\partial^{2} w_{0}}{\partial y^{2}} \frac{\partial^{2} w}{\partial x^{2}}\right]
$$

In these equations, $w$ is the plate deflection, $w_{0}$ is the initial geometric imperfection, $\phi$ is the Airy stress function, $E$ is the elastic modulus, $t$ is the (constant) plate thickness, $p_{z}$ is the lateral pressure on the plate and $D$ is the flexural rigidity of the plate, given by:

$\mathrm{D}=\frac{E t^{3}}{12\left(1-v^{2}\right)}$

In the above equation, $v$ is the Poisson's ratio of the material. The $x-y$ coordinate system is contained within the undeformed midplane of the plate. It is noted that the addition of the imperfection terms in Eqs. (1-2) should actually be credited to Marguerre (1939).

The von Karman equations can be seen as an extension of the work by Saint-Venant (1883), who was first to derive a differential equation describing the stability of elastic plates:

$$
D\left[\frac{\partial^{4} w}{\partial x^{4}}+2 \frac{\partial^{4} w}{\partial x^{2} \partial y^{2}}+\frac{\partial^{4} w}{\partial y^{4}}\right]=\sigma_{x} t \frac{\partial^{2} w}{\partial x^{2}}+\sigma_{y} t \frac{\partial^{2} w}{\partial y^{2}}+2 \tau_{x y} t \frac{\partial^{2} w}{\partial x \partial y}
$$

In the above equation, $\sigma_{x}, \sigma_{y}$ and $\tau_{x y}$ are the membrane normal stresses in the $x$ - and $y$-directions and the membrane shear stress, respectively. As opposed to Eqs. (1-2), Eq. (4) has the advantage of being a single differential equation which is linear. However, it does not account for the change in the membrane stresses resulting from the plate deflections. It can therefore be used to determine the buckling stress of a plate under a given loading, but not to determine the behaviour of the plate in the post-buckling range. 
The von Karman equations account for the possible presence of geometric imperfections, but assume a linear elastic material behaviour, which inherently limits their practical relevance. However, the biggest impediment to their practical application is that, while solutions exist for a few specific cases, a general solution appears to be beyond reach. Levy (1942) succeeded in obtaining a solution expressed as a Fourier series for the case of a rectangular plate subjected to a combination of uniaxial in-plane compressive loading and a lateral pressure $p_{z}$. However, implementing the solution for a particular configuration is rather computationally demanding. Approximate solutions to the von Karman equations can be obtained using energy methods and this approach was used by, among others, Cox (1933), Marguerre (1937), Marguerre and Trefftz (1937), Yamaki (1959), Timoshenko and Gere (1961), Graves Smith (1969), Rhodes and Harvey (1971), Okada et al. (1979), Ueda et al. (1987) and Nedelcu (2020).

The first investigation of the post-buckling behaviour of plates displaying inelastic stress-strain behaviour can be attributed to Mayers and Budiansky (1955), who also used an energy method. The investigators assumed that the plate initially buckled elastically, but that plasticity emerged in the post-buckling range, which they modelled using deformation theory.

As an alternative to energy methods, other researchers, most notably Walker (1969) and Shen (1989), used a perturbation method to obtain approximate solutions to the von Karman equations, valid in the neighbourhood of the buckling load. A discussion on the mathematical subtleties of deriving an initial post-buckling stiffness from the von Karman equations was provided by Guarracino (2007).

A comprehensive overview of plate analysis methods, discussing the evolution of earlier stage techniques, is found in Aalami and Williams (1979) and Chia (1980).

Rather than developing semi-analytical solutions, which typically requires intensive hand calculations, numerical (computer-based) methods based on domain discretization have become very popular since the 1960s. Finite differences schemes for elastic plates have been developed by Basu and Chapman (1966), Brown and Harvey (1969), Reddy and Gera (1979), Satyamurthy et al. (1980), Turvey and Der Avanassian (1986) and Assadi-Lamouki and Krauthammer (1989). A finite difference method accounting for flow theory based plasticity, able to predict the ultimate inelastic capacity of plates, was presented by Becque (2014). However, the most versatile and commonly employed numerical method is no doubt the Finite Element (FE) method; 2D shell elements are typically used to model plated structures, and commercial FE packages offer a multitude of shell element formulations suited for various applications. Additionally, within the scientific research community focused on thin-walled structures the Finite Strip Method (FSM) is a popular alternative to FE analysis. In its original form, developed by Przemieniecki (1973), Planck and Wittrick (1974) and 
Cheung (1976), the FSM is able to carry out an elastic stability analysis of a plate assembly, assuming harmonic displacement functions in the longitudinal direction, inspired by the analytical solutions, and using polynomial approximations in the transverse direction. The FSM was extended by Graves Smith and Sridharan (1978) to model the elastic post-buckling range of thin-walled members, followed by further work by Key and Hancock (1993) to also account for inelastic material behaviour, imperfections and residual stresses. A variation of the FSM, the spline finite strip method, originally developed by Fan (1982), has also been used by Lau and Hancock (1986) and Kwon and Hancock (1991) to investigate the elastic and inelastic post-buckling behaviour of thin-walled cross-sections under various loading.

Generalized Beam Theory (GBT) also deserves mention as a potential tool to investigate the postbuckling behaviour of thin-walled cross-sections and this option was pursued by, among others, Silvestre and Camotim (2003), Basaglia et al. (2011) and Ruggerini et al. (2019).

Given the large amount of effort which has been invested in the theoretical study of the postbuckling behaviour of plates and plate assemblies, it is to some extent regretful that this extensive body of work becomes largely irrelevant in the practical design against local buckling. Indeed, all major design standards around the world instead rely on the purely empirically derived Winter equation (Winter 1940, Winter 1970) to obtain ultimate capacities for local buckling:

$$
\frac{\mathrm{P}_{\mathrm{u}}}{\mathrm{P}_{\mathrm{y}}}=\frac{1}{\lambda}\left(1-\frac{0.22}{\lambda}\right) \leq 1.0
$$

where $P_{u}$ is the ultimate capacity of the plate in compression, $P_{y}$ is the yield load and $\lambda$ is the slenderness, given by:

$\lambda=\sqrt{\frac{f_{y}}{\sigma_{c r}}}$

In the above equation $f_{y}$ is the yield strength and $\sigma_{c r}$ is the elastic critical local buckling stress.

The aims of this paper are to deduce approximate equations describing the post-buckling behaviour of plates and, of equal importance, to develop Winter-type design equations from these solutions to calculate the ultimate capacity of plates displaying imperfections and plasticity. This establishes, for the first time, a link between the theoretical framework of the von Karman equations and the practical design of plates. Contrary to previous approaches the von Karman equations are not solved in their complete form (Eqs. 1-2) using semi-analytical or numerical techniques. Rather, Eqs. (1-2) are first simplified into a single equation, using rational assumptions which agree well with observed 
plate behaviour. Crucially, this is done in such a way that the resulting model still captures the essence of the post-buckling mechanics of plates, in particular the mechanisms which drive the further development of the mid-plane membrane stresses. Although approximate, this approach allows in many cases to derive closed form expressions for the plate deformations as a function of the loading. The scope of this paper is limited to rectangular plates under uniaxial compressive inplane loading. Two cases of boundary conditions are considered, as illustrated in Fig. 1. In both cases the loaded edges $(x=0$ and $x=L)$ remain straight in the post-buckling range. This corresponds to the practical case of a plate element in a long column, where straight 'nodal lines' develop in between buckled cells. For the longitudinal edges (parallel to the loading) two cases are considered: case A, where the edges are free to pull in during the post-buckling stage (Fig. 1a), and case B, where the edges can move in while remaining straight (Fig. 1b). Case A is most representative of a plate (e.g. a web) in an actual column, since the bending stiffness of the adjacent plates (e.g. the flanges) about a transverse axis in their plane is typically fairly limited and certainly insufficient to create a situation

\section{Simplifying the von Karman equations}

In order to simplify Eqs. (1-2), it is clear that some additional assumptions are necessary. The inspiration for these is provided by the effective width concept, which is also credited to von Karman (von Karman et al. 1932). This concept is based on the observation that in the post-local buckling range the longitudinal stresses shift towards the longitudinal edges of the plate and can thus be idealized as being carried by two strips adjacent to those edges. The widths of these effective strips are obtained by equating the integral sums of the actual and idealized stress distributions over the width of the plate (Fig. 1). Failure is assumed to occur when the effective strips yield. While this failure criterion will be employed later in the derivation, a major implication of this idealized stress distribution which proves useful for our objectives at this stage (although easily overlooked and seldom questioned) is that the longitudinal membrane stress $\sigma_{x}$ is only a function of the transverse co-ordinate $y$ and is constant along a 'fibre' in the longitudinal $x$-direction: function: 
However, because of the symmetry of the problem, the mixed term in $\mathrm{x}$ and $\mathrm{y}$ has to vanish. Indeed, the stress function $\phi$ cannot have an anti-symmetric component in the $y$-direction. Consequently, the membrane shear stresses in the plate have to be zero:

167

168

$$
\tau_{x y}=-\frac{\partial^{2} \phi}{\partial x \partial y}=0
$$

This can be seen as an extension of Vlasov's assumption into the post-buckling range. Eq. (9) is consistent with the view presented by Eq. (7) that each longitudinal mid-plane fibre acts independently, carrying a constant stress $\sigma_{\mathrm{x}}$ along its length, while not partaking in any direct load sharing with its neighbours through shear stresses. The additional implication of Eq. (8) (with $c(x)=0)$ is that the transverse membrane stress $\sigma_{y}$ is equally independent of $y$ :

$$
\sigma_{\mathrm{y}}=\frac{\partial^{2} \phi}{\partial \mathrm{x}^{2}}=\mathrm{h}(\mathrm{x})
$$

The straining of a longitudinal fibre can then be determined from its deflected shape as follows (Fig. 3):

$$
\begin{aligned}
\varepsilon_{\mathrm{x}} & =\frac{1}{\mathrm{~L}}\left\{\left[\int \mathrm{ds}\right]-\mathrm{L}\right\}=\frac{1}{\mathrm{~L}}\left\{\left[\int \sqrt{(\mathrm{dx})^{2}+(\mathrm{dw})^{2}}\right]-\mathrm{L}\right\}=\frac{1}{\mathrm{~L}}\left\{\left[\int_{0}^{\mathrm{L}-\mathrm{U}_{0}} \sqrt{1+\left(\frac{\partial \mathrm{w}}{\partial \mathrm{x}}\right)^{2}} \mathrm{dx}\right]-\mathrm{L}\right\} \\
& \approx \frac{1}{\mathrm{~L}}\left\{\left[\int_{0}^{\mathrm{L}-\mathrm{U}_{0}}\left(1+\frac{1}{2}\left(\frac{\partial \mathrm{w}}{\partial \mathrm{x}}\right)^{2}\right) \mathrm{dx}\right]-\mathrm{L}\right\} \approx \frac{1}{2 \mathrm{~L}}\left[\int_{0}^{\mathrm{L}}\left(\frac{\partial \mathrm{w}}{\partial \mathrm{x}}\right)^{2} \mathrm{dx}-2 \mathrm{U}_{0}\right]
\end{aligned}
$$

182

$$
\sigma_{\mathrm{x}}=\frac{\mathrm{E}}{2 \mathrm{~L}}\left[\int_{0}^{\mathrm{L}}\left(\frac{\partial \mathrm{w}}{\partial \mathrm{x}}\right)^{2} \mathrm{dx}-2 \mathrm{U}_{0}\right]
$$
applied load P as follows:

$$
P=-t \int_{0}^{b} \sigma_{x} d y
$$

where $U_{0}$ is the uniform end shortening, as shown in Fig. 1a, and $s$ is the distance measured along the mid-plane fibre. $L$ is the initial length of the plate. The shortening $U_{0}$ can be related to the total

where $b$ is the width of the plate and: 
197

$$
\gamma\left[\frac{\partial^{4} w}{\partial x^{4}}+2 \frac{\partial^{4} w}{\partial x^{2} \partial y^{2}}+\frac{\partial^{4} w}{\partial y^{4}}\right]=\left[\int_{0}^{L}\left(\frac{\partial w}{\partial x}\right)^{2} d x-2 U_{0}\right]\left(\frac{\partial^{2} w}{\partial x^{2}}\right)
$$

198

199

200

201

202

203

204

205

206

207

208

209

$$
\begin{aligned}
\varepsilon_{\mathrm{x}} & =\frac{1}{\mathrm{~L}_{0}}\left\{\int_{0}^{\mathrm{L}-\mathrm{U}_{0}}\left[1+\frac{1}{2}\left(\frac{\partial\left(\mathrm{w}+\mathrm{w}_{0}\right)}{\partial \mathrm{x}}\right)^{2}\right] \mathrm{dx}-\int_{0}^{\mathrm{L}}\left[1+\frac{1}{2}\left(\frac{\partial \mathrm{w}_{0}}{\partial \mathrm{x}}\right)^{2}\right] \mathrm{dx}\right\} \\
& =\frac{1}{\mathrm{~L}_{0}}\left\{\frac{1}{2} \int_{0}^{\mathrm{L}}\left[\left(\frac{\partial \mathrm{w}}{\partial \mathrm{x}}\right)^{2}+2\left(\frac{\partial \mathrm{w}}{\partial \mathrm{x}}\right)\left(\frac{\partial \mathrm{w}_{0}}{\partial \mathrm{x}}\right)\right] \mathrm{dx}-\mathrm{U}_{0}\right\}
\end{aligned}
$$

$$
\approx \frac{1}{2 \mathrm{~L}}\left\{\int_{0}^{\mathrm{L}}\left[\left(\frac{\partial \mathrm{w}}{\partial \mathrm{x}}\right)^{2}+2\left(\frac{\partial \mathrm{w}}{\partial \mathrm{x}}\right)\left(\frac{\partial \mathrm{w}_{0}}{\partial \mathrm{x}}\right)\right] \mathrm{dx}-2 \mathrm{U}_{0}\right\}
$$

210

where $L_{0}$ is the length measured along the imperfect shape before loading. Consequently:

$$
\sigma_{\mathrm{x}}=\frac{\mathrm{E}}{2 \mathrm{~L}}\left\{\int_{0}^{\mathrm{L}}\left[\left(\frac{\partial \mathrm{w}}{\partial \mathrm{x}}\right)^{2}+2\left(\frac{\partial \mathrm{w}}{\partial \mathrm{x}}\right)\left(\frac{\partial \mathrm{w}_{0}}{\partial \mathrm{x}}\right)\right] \mathrm{dx}-2 \mathrm{U}_{0}\right\}
$$

212 The governing differential equation for an imperfect plate (replacing Eq. 14) then becomes:

$$
\gamma\left[\frac{\partial^{4} w}{\partial x^{4}}+2 \frac{\partial^{4} w}{\partial x^{2} \partial y^{2}}+\frac{\partial^{4} w}{\partial y^{4}}\right]=\left[\int_{0}^{L}\left[\left(\frac{\partial w}{\partial x}\right)^{2}+2\left(\frac{\partial w}{\partial x}\right)\left(\frac{\partial w_{0}}{\partial x}\right)\right] d x-2 U_{0}\right]\left(\frac{\partial^{2}\left(w+w_{0}\right)}{\partial x^{2}}\right)
$$


When the boundary conditions are determined by case $B$, the transverse membrane stresses $\sigma_{y}$ are no longer negligible. Owing to the assumed absence of shear stresses, however, the transverse membrane stress can be related to the elongation of a transverse fibre employing a rationale completely analogous to Eq. (11), leading to the following equation:

$$
\sigma_{\mathrm{y}}=\frac{\mathrm{E}}{2 \mathrm{~L}}\left[\int_{0}^{\mathrm{b}}\left(\frac{\partial \mathrm{w}}{\partial \mathrm{y}}\right)^{2} \mathrm{dy}-2 \mathrm{U}_{1}\right]
$$

In the above equation $U_{1}$ is the uniform shortening of the plate in the transverse direction (Fig. 1b), which can be determined from the condition that, while transverse stresses are necessarily present along the edges to keep them straight, their resultant is zero since there is no load applied in this direction:

$$
\mathrm{t} \int_{0}^{\mathrm{L}} \sigma_{\mathrm{y}} \mathrm{dy}=0
$$

and thus, substituting Eq. (19) into Eq. (20):

$$
\mathrm{U}_{1}=\frac{1}{2 \mathrm{~L}} \int_{0}^{\mathrm{L}} \int_{0}^{\mathrm{b}}\left(\frac{\partial \mathrm{w}}{\partial \mathrm{y}}\right)^{2} \mathrm{dxdy}
$$

Using Eqs. (13), (19) and (9), Eq. (1) takes on the form:

$$
\gamma\left[\frac{\partial^{4} w}{\partial x^{4}}+2 \frac{\partial^{4} w}{\partial x^{2} \partial y^{2}}+\frac{\partial^{4} w}{\partial y^{4}}\right]=\left[\int_{0}^{\mathrm{L}}\left(\frac{\partial w}{\partial x}\right)^{2} d x-2 U_{0}\right]\left(\frac{\partial^{2} w}{\partial x^{2}}\right)+\left[\int_{0}^{b}\left(\frac{\partial w}{\partial y}\right)^{2} d y-2 U_{1}\right]\left(\frac{\partial^{2} w}{\partial y^{2}}\right)
$$

Eq. (22) is again independent of the Airy stress function.

When an initial imperfection $w_{0}$ is accounted for, this equation becomes:

$\gamma\left[\frac{\partial^{4} \mathrm{w}}{\partial \mathrm{x}^{4}}+2 \frac{\partial^{4} \mathrm{w}}{\partial \mathrm{x}^{2} \partial \mathrm{y}^{2}}+\frac{\partial^{4} \mathrm{w}}{\partial \mathrm{y}^{4}}\right]=\left[\int_{0}^{\mathrm{L}}\left[\left(\frac{\partial \mathrm{w}}{\partial \mathrm{x}}\right)^{2}+2\left(\frac{\partial \mathrm{w}}{\partial \mathrm{x}}\right)\left(\frac{\partial \mathrm{w}_{0}}{\partial \mathrm{x}}\right)\right] \mathrm{dx}-2 \mathrm{U}_{0}\right]\left(\frac{\partial^{2}\left(\mathrm{w}+\mathrm{w}_{0}\right)}{\partial \mathrm{x}^{2}}\right)$

$$
+\left[\int_{0}^{\mathrm{b}}\left[\left(\frac{\partial \mathrm{w}}{\partial \mathrm{y}}\right)^{2}+2\left(\frac{\partial \mathrm{w}}{\partial \mathrm{y}}\right)\left(\frac{\partial \mathrm{w}_{0}}{\partial \mathrm{y}}\right)\right] \mathrm{dy}-2 \mathrm{U}_{1}\right]\left(\frac{\partial^{2}\left(\mathrm{w}+\mathrm{w}_{0}\right)}{\partial \mathrm{y}^{2}}\right)
$$

To evaluate whether the simplifying assumptions employed in this section to arrive at the differential equations (14), (18), (22) and (23) are realistic, a geometrically non-linear finite element (FE) analysis was carried out of a slender square plate $(\mathrm{L}=\mathrm{b}=200 \mathrm{~mm} ; \mathrm{t}=1 \mathrm{~mm}$ ) with elastic properties ( $\mathrm{E}=200 \mathrm{GPa} ; v=0.3$ ) using Abaqus (2017). Boundary conditions were applied which were commensurate with Case A and the results are presented in Fig. 5 in the form of stress contours for 

the longitudinal membrane stresses $\sigma_{x}$, the shear membrane stresses $\tau_{x y}$ and the transverse membrane stresses $\sigma_{y}$. The stress state was captured at the moment when the maximum longitudinal membrane stress reached $350 \mathrm{MPa}$. According to the effective width concept, this represents the state of failure of a steel plate with yield stress $f_{y}=350 \mathrm{MPa}$ and, given the slenderness of the plate, corresponds to a state well into the post-buckling range. The leftmost diagram in Fig. 5 shows that the $\sigma_{x}$ contours form approximately vertical lines, thus confirming the assumption embedded in Eq. (7). The $\tau_{x y}$ plot (centre), as expected, shows some localized shear stress concentrations near the corners of the plate, which reach up to $34 \mathrm{MPa}$. However, over most of the plate $\tau_{x y}$ remains limited to $5 \mathrm{MPa}$ in absolute value (indicated by the pale green colours). Since this constitutes less than $2 \%$ of the maximum longitudinal membrane stress, the $\tau_{x y}$ stresses can indeed reasonably be neglected. The plot of the transverse membrane stresses $\sigma_{y}$ (rightmost diagram in Fig. 5) shows some stress concentrations near the transverse edges. However, in the central area of the plate stresses do not exceed $19 \mathrm{MPa}$ (=5.5\% of $350 \mathrm{MPa})$. This instils confidence that the assumption of zero transverse membrane stress is a reasonable approximation for a plate with Case A boundary conditions.

\section{Geometrically perfect plate with boundary conditions A}

We consider the case of a square plate $(b=L)$ without imperfections $\left(w_{0}=0\right)$ with case $A$ boundary conditions and we propose the following approximate solution to Eq. (14):

$$
\mathrm{w}=\mathrm{A}_{11} \sin \left(\frac{\pi \mathrm{x}}{\mathrm{L}}\right) \sin \left(\frac{\pi \mathrm{y}}{\mathrm{L}}\right)
$$

Eq. (24) is the solution to the classical Saint-Venant plate equation. In the context of Eq. (14), Eq. (24) can be seen as the first term of a Fourier series, which, by virtue of being the solution to the SaintVenant equation, is dominant in the initial post-buckling range over the remaining terms. Substituting Eq. (24) into Eq. (14) leads to:

$$
\left[4 \gamma\left(\frac{\pi}{\mathrm{L}}\right)^{4}-2 \mathrm{U}_{0}\left(\frac{\pi}{\mathrm{L}}\right)^{2}\right] \sin \left(\frac{\pi \mathrm{x}}{\mathrm{L}}\right) \sin \left(\frac{\pi \mathrm{y}}{\mathrm{L}}\right)=-\mathrm{A}_{11}^{2} \frac{\mathrm{L}}{2}\left(\frac{\pi}{\mathrm{L}}\right)^{4} \sin \left(\frac{\pi \mathrm{x}}{\mathrm{L}}\right) \sin ^{3}\left(\frac{\pi \mathrm{y}}{\mathrm{L}}\right)
$$

This equation can be re-arranged into:

$$
\left[4 \gamma-2 \mathrm{U}_{0}\left(\frac{\mathrm{L}}{\pi}\right)^{2}\right] \sin \left(\frac{\pi \mathrm{x}}{\mathrm{L}}\right) \sin \left(\frac{\pi \mathrm{y}}{\mathrm{L}}\right)=-\mathrm{A}_{11}^{2}\left[\frac{3 \mathrm{~L}}{8} \sin \left(\frac{\pi \mathrm{x}}{\mathrm{L}}\right) \sin \left(\frac{\pi \mathrm{y}}{\mathrm{L}}\right)-\frac{\mathrm{L}}{8} \sin \left(\frac{\pi \mathrm{x}}{\mathrm{L}}\right) \sin \left(\frac{3 \pi \mathrm{y}}{\mathrm{L}}\right)\right]
$$


It is now clear that Eq. (24) cannot be an exact solution to Eq. (14), since higher order Fourier terms are necessary in Eq. (24) in order for the terms in $\sin (\pi x / L) \sin (3 \pi y / L)$ in Eq. (26) to vanish. However, employing the orthogonality property of the Fourier terms, the total coefficient of $\sin (\pi x / L) \sin (\pi y / L)$ in Eq. (26) can be set equal to zero, leading to:

$$
\mathrm{A}_{11}^{2}=-\frac{8}{3 \mathrm{~L}}\left[4 \gamma-2 \mathrm{U}_{0}\left(\frac{\mathrm{L}}{\pi}\right)^{2}\right]
$$

On the other hand, Eq. (12) results in:

$$
\begin{aligned}
\mathrm{P} & =\frac{\mathrm{tE}}{2 \mathrm{~L}}\left[2 \mathrm{U}_{0} \mathrm{~L}-\int_{0}^{\mathrm{L}} \int_{0}^{\mathrm{L}}\left(\frac{\partial \mathrm{w}}{\partial \mathrm{x}}\right)^{2} \mathrm{dxdy}\right] \\
& =\frac{\mathrm{tE}}{2 \mathrm{~L}}\left[2 \mathrm{U}_{0} \mathrm{~L}-\int_{0}^{\mathrm{L}} \int_{0}^{\mathrm{L}} \mathrm{A}_{11}^{2}\left(\frac{\pi}{\mathrm{L}}\right)^{2} \cos ^{2}\left(\frac{\pi \mathrm{x}}{\mathrm{L}}\right) \sin ^{2}\left(\frac{\pi \mathrm{y}}{\mathrm{L}}\right) \mathrm{dxdy}\right] \\
& =\frac{\mathrm{Et}}{8}\left[8 \mathrm{U}_{0}-\mathrm{A}_{11}^{2} \frac{\pi^{2}}{\mathrm{~L}}\right]
\end{aligned}
$$

Substituting Eq. (27) into Eq. (28) yields the load-shortening relationship in the post-buckling range:

$$
\mathrm{P}=\mathrm{Et}\left[\frac{\mathrm{U}_{0}}{3}+\frac{4}{3} \gamma\left(\frac{\pi}{\mathrm{L}}\right)^{2}\right]
$$

In the initial pre-buckled state: $\mathrm{P}=\mathrm{EtU}_{0}$. Thus, Eq. (29) shows that the predicted initial post-buckling stiffness equals $1 / 3$ of the pre-buckling stiffness. Marguerre (1937) reported a more exact value for this ratio, which depends on the Poisson's ratio $v$, but ranges from 0.34 (for $v=0.5$ ) to 0.41 (for $v=$ $0)$. For steel plates $(v=0.3)$ the value is 0.38 , which differs by $12 \%$ from our estimate. Koiter and Pignataro (1976) equally found an approximate value of $1 / 3$ based on a minimum potential energy approach (see also: Thompson and Hunt 1984). Figure 6 compares the (linear) load-shortening behaviour predicted by Eq. (29) with the results of the FE model of a steel plate with $L=b=200 \mathrm{~mm}$ and $\mathrm{t}=1 \mathrm{~mm}$ (previously introduced in Fig. 5). It should thereby be noted that a minute imperfection of $0.004 \mathrm{~mm}$ was introduced into the FE model. This was necessary in order to avoid Abaqus continuing the analysis on the (unstable) unbuckled equilibrium path past the critical stress. Owing to the very small magnitude of the imperfection (which was chosen as small as possible by trial-anderror), its effect on the results is thought to be very limited. Figure 6a shows that the initial postbuckling stiffness of the plate is well matched by Eq. (29). This stiffness was predicted by the FE model to be $0.32 \times E$ and, despite the transition around the bifurcation point being the most imperfection-sensitive region, this result agrees well with both Marguerre's theoretical prediction and the prediction of Eq. (29). It is also seen that Eq. (29) provides a good representation of the post- 
buckling behaviour up to a shortening of about $0.1 \mathrm{~mm}$, corresponding to a strain of approximately $5 \times 10^{-4}$ or 5.5 times the strain at buckling.

A relationship between the load $P$ and the deflection $A_{11}$ at the centre of the plate in the postbuckling range can be derived by eliminating $U_{0}$ from Eqs. (27) and (29):

$$
\mathrm{A}_{11}^{2}=\frac{16}{\mathrm{~L}}\left[\left(\frac{\mathrm{L}}{\pi}\right)^{2} \frac{\mathrm{P}}{\mathrm{Et}}-2 \gamma\right]
$$

A comparison of Eq. (30) with the results of the FE analysis in Fig. $6 \mathrm{~b}$ reveals good agreement up to plate deflections of 5-6 times the plate thickness.

The plate first buckles when $A_{11}=0$, which according to Eq. (27) happens when:

$$
\mathrm{U}_{0}=2 \gamma\left(\frac{\pi}{\mathrm{L}}\right)^{2}
$$

Substituting this value into Eq. (29) yields the expected result:

$$
P_{c r}=2 \operatorname{Et\gamma }\left(\frac{\pi}{L}\right)^{2}=\frac{4 \pi^{2} E}{12\left(1-v^{2}\right)}\left(\frac{t}{L}\right)^{2} L t=\sigma_{c r} A
$$

where $A$ is the cross-sectional area of the plate in the transverse direction. Using Eq. (32) to eliminate $\gamma$, and defining the average longitudinal strain in the plate as $\varepsilon=U_{0} / L$ and the average longitudinal stress as $\sigma=\mathrm{P} / \mathrm{A}$, the load-shortening equation (29) can also be written in a more general form as:

$$
\frac{\sigma}{\sigma_{\mathrm{cr}}}=\frac{1}{3}\left[\frac{\varepsilon}{\varepsilon_{\mathrm{cr}}}+2\right]
$$

where the strain at buckling $\varepsilon_{\mathrm{cr}}=\sigma_{\mathrm{cr}} / \mathrm{E}$.

The profile of the longitudinal membrane stresses is given by Eq. (13):

$$
\sigma_{x}=\frac{E}{2 L}\left[\left(\frac{\pi}{L}\right)^{2} \int_{0}^{L} A_{11}^{2} \cos ^{2}\left(\frac{\pi x}{L}\right) \sin ^{2}\left(\frac{\pi y}{L}\right) d x-2 U_{0}\right]=\frac{E}{2 L}\left[A_{11}^{2}\left(\frac{\pi^{2}}{2 L}\right) \sin ^{2}\left(\frac{\pi y}{L}\right)-2 U_{0}\right]
$$

According to the effective width concept failure occurs when the maximum longitudinal membrane stress (occurring at $y=0$ and $y=L$ according to the above equation) reaches the yield stress:

$$
\left|\sigma_{\mathrm{x}, \max }\right|=\frac{\mathrm{EU}_{0}}{\mathrm{~L}}=\mathrm{f}_{\mathrm{y}}
$$



now becomes:

350

where $P_{u}$ is the ultimate load of the plate, $P_{y}=A f_{y}$ is the yield load and $\lambda$ is the slenderness previously defined in Eq. (6). Eq. (36) is reminiscent of the Winter equation and both equations are compared in Figure 7 (blue and black lines). It is seen that, while both equations exhibit a similar trend, Eq. (36) results in significantly higher predictions of the plate capacity. It will be demonstrated in the following sections of this paper that for lower slenderness values $\lambda$ this discrepancy is mainly due to the fact that imperfections have not yet been accounted for, while for higher slenderness values the approximate character of the solution proposed in Eq. (24) is principally at fault.

\section{Geometrically perfect plate with boundary conditions B}

Eq. (24) can also be substituted in Eq. (22) describing the post-buckling behaviour of a plate with four straight edges. It is again assumed that the plate is square $(b=L)$ and geometrically perfect ( $w_{0}$ $=0)$. Applying the same methodology as employed in the previous section results in the loadshortening relationship:

$$
\mathrm{P}=\mathrm{Et}\left[\gamma\left(\frac{\pi}{\mathrm{L}}\right)^{2}+\frac{\mathrm{U}_{0}}{2}\right]
$$

Eq. (37) shows that, for these boundary conditions, the initial stiffness in the post-buckling range is half of the pre-buckling stiffness, thus exactly confirming the results found by Marguerre (1937) and Koiter and Pignataro (1976).

Using the failure criterion presented in Eq. (35) can be shown to result in the following equation for the ultimate capacity of the plate:

$$
\frac{\mathrm{P}_{\mathrm{u}}}{\mathrm{P}_{\mathrm{y}}}=\frac{1}{2}\left(1+\frac{1}{\lambda^{2}}\right)
$$

Eq. (38) is also plotted in Figure 7 in dashed green line, although it should not be directly compared with the Winter equation, as longitudinal edges were not kept straight in Winter's tests. 
400

401

402

403

404

485

407

408

409

410

In most practical applications, the boundary conditions can be approximated by case A, and few instances can be found of case B boundary conditions. The remainder of the paper will therefore focus on case $A$.

\section{Geometrically imperfect plate with boundary conditions A}

We consider a square plate with boundary conditions $A$, which is assumed to have an imperfection $w_{0}$ described by the following equation:

$$
\mathrm{w}_{0}=\mathrm{A}_{0} \sin \left(\frac{\pi \mathrm{x}}{\mathrm{L}}\right) \sin \left(\frac{\pi \mathrm{y}}{\mathrm{L}}\right)
$$

Substituting the proposed solution Eq. (24), as well as the above expression Eq. (39), into Eq. (18) leads to the following result:

$$
\frac{3 \mathrm{~L}}{8} \mathrm{~A}_{11}^{3}+\frac{9 \mathrm{~L}}{8} \mathrm{~A}_{0} \mathrm{~A}_{11}^{2}+\left[4 \gamma-2 \mathrm{U}_{0}\left(\frac{\mathrm{L}}{\pi}\right)^{2}+\frac{3 \mathrm{~L}}{4} \mathrm{~A}_{0}^{2}\right] \mathrm{A}_{11}-2 \mathrm{U}_{0}\left(\frac{\mathrm{L}}{\pi}\right)^{2} \mathrm{~A}_{0}=0
$$

On the other hand, substituting Eqs. (24) and (39) into Eq. (17), followed by application of Eq. (12) leads to:

$$
\mathrm{P}=\mathrm{Et}\left[\mathrm{U}_{0}-\frac{\pi^{2}}{8 \mathrm{~L}} \mathrm{~A}_{11}\left(\mathrm{~A}_{11}+2 \mathrm{~A}_{0}\right)\right]
$$

Eliminating $A_{11}$ from Eqs. (40) and (41) results in the following implicit load-shortening relationship:

$$
\frac{1}{4 \gamma}\left(\frac{\mathrm{L}}{\pi}\right)^{2}\left(\mathrm{U}_{0}-\frac{3 \mathrm{P}}{\mathrm{Et}}\right)=\frac{1}{\sqrt{1-\frac{8 \mathrm{~L}}{\pi^{2} \mathrm{~A}_{0}^{2}}\left(\frac{\mathrm{P}}{\mathrm{Et}}-\mathrm{U}_{0}\right)}}-1
$$

Eq. (42) can also be expressed in terms of the variables e $=\varepsilon / \varepsilon_{\mathrm{cr}}$ and $\mathrm{s}=\sigma / \sigma_{\mathrm{cr}}$ :

$$
\frac{1}{2}(\mathrm{e}-3 \mathrm{~s})=\frac{1}{\sqrt{1-(\mathrm{s}-\mathrm{e}) / \alpha_{\mathrm{cr}}}}-1
$$

with:

$$
\alpha_{c r}=\frac{\pi^{2} \mathrm{E}}{8 \sigma_{\mathrm{cr}}}\left(\frac{\mathrm{A}_{0}}{\mathrm{~L}}\right)^{2}
$$

Eq. (43) was solved numerically for various values of e and the results were compared to the FE results obtained for the previously introduced square steel plate $(L=200 \mathrm{~mm} ; \mathrm{t}=1 \mathrm{~mm})$ (Figure 8). 
$416 \lim _{\mathrm{U}_{0} \rightarrow \infty} \frac{\mathrm{dP}}{\mathrm{dU}_{0}}=\frac{\mathrm{Et}}{3}$ deflections increase.

$\alpha=\frac{\pi^{2} \mathrm{E}}{8 \mathrm{f}_{\mathrm{y}}}\left(\frac{\mathrm{A}_{0}}{\mathrm{~L}}\right)^{2}$

Both Eq. (43) and the FE model incorporated an initial imperfection $A_{0}=1 \mathrm{~mm}$. Good agreement was obtained up to strains of about 5 times the buckling strain $\varepsilon_{c r}$.

It also follows from Eqs. (40) and (41) that:

This result shows that Eq. (42) asymptotically approaches the behaviour of a perfect plate as

Taking Eq. (42) as a starting point and making use of the failure criterion in Eq. (35) to eliminate $U_{0}$, the following analogue for the Winter equation is obtained:

$\frac{1}{\lambda^{2}}=\frac{1}{2}\left(3 \frac{\mathrm{P}_{\mathrm{u}}}{\mathrm{P}_{\mathrm{y}}}-1\right)\left(1+\frac{1}{\sqrt{1+\frac{1}{\alpha}\left(1-\frac{\mathrm{P}_{\mathrm{u}}}{\mathrm{P}_{\mathrm{y}}}\right)}-1}\right)$

In the above equation $\alpha$ is an imperfection factor, which is given by:

According to Eurocode 3: EN1993-1-5 (CEN 2006) the local imperfection of a plate supported along all four edges may be taken as $A_{0}=b / 200$ (where $b$ is the width of the plate, in this case equal to the length L). This 'equivalent' imperfection takes into account geometric imperfections, as well as residual stresses. With $E=200 \mathrm{GPa}$ and $\mathrm{f}_{\mathrm{y}}=350 \mathrm{MPa}$, Eq. (47) yields: $\alpha=1 / 57$. Figure 7 shows Eq. (46), plotted for this value of $\alpha$, in solid red line. Very good agreement with the Winter curve is obtained up to a slenderness value of about 1.5-2. For higher slenderness values the predictions diverge from the Winter curve. This can be attributed to the limiting assumptions in our model, in particular the proposition that the deflected shape is represented by Eq. (24). This assumption results in a constant post-buckling stiffness for a perfect plate, as indicated by Eqs. (29) and (37), or an asymptotically constant post-buckling stiffness for an imperfect plate, as indicated by Eq. (45). In reality this stiffness will further deteriorate as the load rises in the post-buckling range, as seen from the FE results in Fig. 6a and Fig. 8. This effect is, of course, more important for more slender plates, which go through a more extended post-buckling range before yielding sets in. This suggests that the predictions of both the plate post-buckling deformations and the plate capacity can be improved in 
the high slenderness range by including higher-order Fourier terms in Eq. (24). This is the topic of the following sections of this paper.

\section{Higher order solution for a perfect plate (Case A)}

A more accurate solution for the post-buckling behaviour of a perfect plate with Case A boundary conditions can be obtained by including not one, but four Fourier terms in the proposed solution for the plate deflections w:

$$
\mathrm{w}=\mathrm{A}_{11} \sin \left(\frac{\pi \mathrm{x}}{\mathrm{L}}\right) \sin \left(\frac{\pi \mathrm{y}}{\mathrm{L}}\right)+\mathrm{A}_{13} \sin \left(\frac{\pi \mathrm{x}}{\mathrm{L}}\right) \sin \left(\frac{3 \pi \mathrm{y}}{\mathrm{L}}\right)+\mathrm{A}_{31} \sin \left(\frac{3 \pi \mathrm{x}}{\mathrm{L}}\right) \sin \left(\frac{\pi \mathrm{y}}{\mathrm{L}}\right)+\mathrm{A}_{33} \sin \left(\frac{3 \pi \mathrm{x}}{\mathrm{L}}\right) \sin \left(\frac{3 \pi \mathrm{y}}{\mathrm{L}}\right)
$$

and substituting this expression in Eq. (14). It is noted that the Fourier terms in $2 x$ and $2 y$ need not be considered because of the symmetry of the problem. The resulting calculations are rather lengthy but quite straightforward and are not reported here. By equating the corresponding coefficients of each Fourier term on the left- and right-hand side of Eq. (14) (noting that these are necessary conditions because of the orthogonality of the Fourier terms) it is discovered that:

$$
\mathrm{A}_{31}=\mathrm{A}_{33}=0
$$

and that the two non-zero coefficients $A_{11}$ and $A_{13}$ are determined by the following non-linear system of equations:

$$
\frac{8}{\mathrm{~L}}\left[4 \gamma-2 \mathrm{U}_{0}\left(\frac{\mathrm{L}}{\pi}\right)^{2}\right]=-3 \mathrm{~A}_{11}^{2}+3 \mathrm{~A}_{11} \mathrm{~A}_{13}-6 \mathrm{~A}_{13}^{2}
$$

$$
\frac{8}{\mathrm{~L}}\left[100 \gamma-2 \mathrm{U}_{0}\left(\frac{\mathrm{L}}{\pi}\right)^{2}\right] \mathrm{A}_{13}=\mathrm{A}_{11}^{3}-6 \mathrm{~A}_{11}^{2} \mathrm{~A}_{13}-3 \mathrm{~A}_{13}^{3}
$$

Eq. (49) indicates that the longitudinal shape of the buckling pattern does not change in the postbuckling range and remains a single sinusoidal half-wave. This is, of course, a result of the simplifying assumptions we have initially made, in particular the assumptions that (1) each longitudinal fibre of the plate behaves independently, mimicking in this sense the behaviour of a column, and (2) the transverse membrane stresses always remain at zero, independently of the longitudinal displacement profile. On the other hand, a change in the transverse displacement profile does have the ability to significantly affect the longitudinal stress distribution, as evidenced by Eq. (13). 
Substituting Eq. (48) into Eq. (13) yields the longitudinal stresses in the plate:

$$
\sigma_{x}=\frac{E}{4}\left(\frac{\pi}{L}\right)^{2}\left[A_{11}^{2} \sin ^{2}\left(\frac{\pi y}{L}\right)+A_{13}^{2} \sin ^{2}\left(\frac{3 \pi y}{L}\right)+A_{11} A_{13} \sin \left(\frac{\pi y}{L}\right) \sin \left(\frac{3 \pi y}{L}\right)\right]-\frac{E_{0}}{L}
$$

which, through Eq. (12), gives the axial compressive load as:

$$
P=E U_{0} t-\frac{\pi^{2} E t}{8 L}\left(A_{11}^{2}+A_{13}^{2}\right)
$$

The above equation describes the relationship between the axial shortening $U_{0}$ of the plate and the load $P$ in the post-buckling range, albeit that $A_{11}$ and $A_{13}$ are functions of $U_{0}$ through Eqs. (50-51). These equations can be solved exactly for $A_{11}$ and $A_{13}$ (e.g. using Solver in Excel (Microsoft, 2017)) for any given value of $U_{0}$, upon which Eq. (53) provides the corresponding load. This procedure was applied to the earlier example of a square plate with $\mathrm{E}=200 \mathrm{GPa}, \mathrm{L}=200 \mathrm{~mm}$ and $\mathrm{t}=1 \mathrm{~mm}$, resulting in the dark green curve in Fig. 9. This curve agrees very well with the results of the FE analysis, also shown (in black) in the same diagram, up to an axial strain of about 20 times the buckling strain. If it is assumed that the plate reaches this strain when yielding of the most compressed fibre occurs (effectively failing the plate according to the effective width concept), then the corresponding plate slenderness $\lambda$ is $\sqrt{20} \approx 4.5$. This slenderness significantly exceeds that of typically encountered plates and plate assemblies in structural applications and it can thus be concluded that this solution is sufficient for almost all practical situations.

Interestingly, an approximate closed form solution can also be obtained. Indeed, Eqs. (50-51) can be further simplified by using the knowledge that the first term in Eq. (48) is (initially) dominant over the second one and that thus $A_{11} \gg A_{13}$. Consequently, the terms in $A_{13}^{2}$ and $A_{13}^{3}$ can in very good approximation be neglected in comparison with the others:

$$
\begin{aligned}
& \frac{8}{\mathrm{~L}}\left[4 \gamma-2 \mathrm{U}_{0}\left(\frac{\mathrm{L}}{\pi}\right)^{2}\right]=-3 \mathrm{~A}_{11}\left(\mathrm{~A}_{11}-\mathrm{A}_{13}\right) \\
& \frac{8}{\mathrm{~L}}\left[100 \gamma-2 \mathrm{U}_{0}\left(\frac{\mathrm{L}}{\pi}\right)^{2}\right] \mathrm{A}_{13}=\mathrm{A}_{11}^{2}\left(\mathrm{~A}_{11}-6 \mathrm{~A}_{13}\right)
\end{aligned}
$$

By eliminating $A_{13}$ from Eqs. (54-55) the following expression is obtained:

$$
\mathrm{A}_{11}^{2}=\frac{4}{15 \mathrm{~L}}\left(-324 \gamma+18 \mathrm{U}_{0}\left(\frac{\mathrm{L}}{\pi}\right)^{2}+\sqrt{80976 \gamma^{2}+816 \gamma \mathrm{U}_{0}\left(\frac{\mathrm{L}}{\pi}\right)^{2}+84 \mathrm{U}_{0}^{2}\left(\frac{\mathrm{L}}{\pi}\right)^{4}}\right)
$$



to $\mathrm{A}_{11}^{2}$ :

512

$$
\mathrm{P}=\frac{\mathrm{ELt}}{15}\left(6 \varepsilon+81 \varepsilon_{\mathrm{cr}}-\sqrt{21 \varepsilon^{2}+102 \varepsilon_{\mathrm{cr}} \varepsilon+5061 \varepsilon_{\mathrm{cr}}^{2}}\right)
$$

or:

516

$$
\mathrm{s}=\frac{1}{15}\left(6 \mathrm{e}+81-\sqrt{21 \mathrm{e}^{2}+102 \mathrm{e}+5061}\right)
$$

518

519

520

521

522

523

524

525

$528 \varepsilon=\frac{\mathrm{f}_{\mathrm{y}}}{\mathrm{E}}$

$$
\frac{\mathrm{P}_{\mathrm{u}}}{\mathrm{P}_{\mathrm{y}}}=\frac{3}{5}\left(\frac{9}{\lambda^{2}}+\frac{2}{3}-\frac{1}{2} \sqrt{\frac{250}{\lambda^{4}}+\frac{5}{\lambda^{2}}+1}\right)
$$

533

Eq. (58) is also shown in Fig. 9 (in pale green line). It is seen that Eq. (58) is initially indistinguishable from the 'exact' solution, up to an average strain of about 10 times the buckling strain. Beyond this range, both solutions diverge slightly, although Eq. (58) always stays within reasonably close range of the FE results up to a strain of at least 30 times the buckling strain (the difference with the FE results at this strain is $6.8 \%)$.

In order to again derive a Winter-type design equation, it is first concluded from inspection of Eq. (52) that the failure criterion represented by Eq. (35) still holds. Thus, substituting:

into Eq. (58) and using the definition of the slenderness $\lambda$ (Eq. 6) results in:

This equation is plotted in Figure 10 (pale green curve) and compared to the actual Winter curve. It is seen that Eq. (60) agrees much better with the Winter curve than Eq. (36), derived using only a single Fourier term, particularly in the high slenderness range $(\lambda>2)$ where plates typically have a much more extended post-buckling range. While following the same trend, Eq. (60) slightly 'hovers' above the Winter equation over the whole slenderness range, which is mainly due to the absence of any imperfections in our model.

A more 'exact' curve can be produced numerically by choosing a range of $U_{0}$ values and calculating, for each $U_{0}, A_{11}$ and $A_{13}$ using Eqs. (50-51), followed by $P$ using Eq. (53). Eq. (59) then yields $f_{y}$ for a given $\varepsilon=\mathrm{U}_{0} / \mathrm{L}$ and Eq. (6) reveals the corresponding slenderness. Plotting all $(\lambda, P)$ pairs results in the dark green curve in Figure 10. This curve is near indistinguishable from the closed form solution 
given by Eq. (60) up to a slenderness of about 3.5 (i.e. within the practical slenderness range) and predicts slightly higher values thereafter.

\section{Higher order solution for an imperfect plate (Case A)}

We now consider a plate containing an initial imperfection described by Eq. (39). Inspired by the conclusions of the preceding section, we assume the displacement profile $w$ to be accurately represented by:

$$
\mathrm{w}=\mathrm{A}_{11} \sin \left(\frac{\pi \mathrm{x}}{\mathrm{L}}\right) \sin \left(\frac{\pi \mathrm{y}}{\mathrm{L}}\right)+\mathrm{A}_{13} \sin \left(\frac{\pi \mathrm{x}}{\mathrm{L}}\right) \sin \left(\frac{3 \pi \mathrm{y}}{\mathrm{L}}\right)
$$

Substitution of Eqs. (39) and (61) in Eq. (18) and separating the Fourier terms eventually leads to the following non-linear system of equations in $A_{11}$ and $A_{13}$ :

$$
\begin{aligned}
\left(\frac{8}{L}\right)\left[4 \gamma A_{11}-2\left(A_{11}+A_{0}\right) U_{0}\left(\frac{L}{\pi}\right)^{2}\right]=-3 A_{11}^{3} & -9 A_{0} A_{11}^{2}+3 A_{11}^{2} A_{13}+6 A_{0} A_{11} A_{13} \\
& -6 A_{11} A_{13}^{2}-6 A_{0}^{2} A_{11}+2 A_{0}^{2} A_{13}-6 A_{0} A_{13}^{2}
\end{aligned}
$$

$$
\mathrm{A}_{13}\left(\frac{8}{\mathrm{~L}}\right)\left[100 \gamma-2 \mathrm{U}_{0}\left(\frac{\mathrm{L}}{\pi}\right)^{2}\right]=\mathrm{A}_{11}^{3}+3 \mathrm{~A}_{0} \mathrm{~A}_{11}^{2}-6 \mathrm{~A}_{11}^{2} \mathrm{~A}_{13}-12 \mathrm{~A}_{0} \mathrm{~A}_{11} \mathrm{~A}_{13}+2 \mathrm{~A}_{0}^{2} \mathrm{~A}_{11}-4 \mathrm{~A}_{0}^{2} \mathrm{~A}_{13}-3 \mathrm{~A}_{13}^{3}
$$

This system of equations can again be solved numerically (e.g. using Solver in Excel (Microsoft, 2007)) for any chosen $U_{0}$ value. The resulting $A_{11}$ and $A_{13}$ values then determine the load $P$ through Eq. (64), which was obtained by substituting Eq. (61) into Eqs. (12-13):

$$
\mathrm{P}=\mathrm{Et}\left[\mathrm{U}_{0}-\frac{\pi^{2}}{8 \mathrm{~L}}\left(\mathrm{~A}_{11}^{2}+2 \mathrm{~A}_{0} \mathrm{~A}_{11}+\mathrm{A}_{13}^{2}\right)\right]
$$

This procedure can be carried out for a range of $U_{0}$ values to obtain a load-shortening curve. An example is shown in Fig. 11 (brown line), where the $200 \times 200 \mathrm{~mm}^{2}$ plate geometry previously considered was revisited with $A_{0}=L / 200=1 \mathrm{~mm}$. This curve is compared to the corresponding graph obtained from FE analysis (black line). A very good agreement is observed for strains up to about 20 times the buckling strain (corresponding to loads of up to 5 times the buckling load). For higher strains, the solution starts to diverge from the FE results due the approximate nature of both the proposed solution Eq. (61) and the newly developed Eq. (18). 
In order to establish a corresponding design curve, the value of $U_{0}$ in the above Eqs. (62-63) can be held constant and linked to a chosen yield stress through Eq. (35). The equations can then be solved for different values of $\gamma$, which determines $\sigma_{\mathrm{cr}}$ through Eq. (32) and thus, for a given yield stress, the slenderness $\lambda$. The resulting load-slenderness curve is the sought equivalent of the Winter curve. This procedure was carried out for $A_{0}=L / 200$ and $f_{y}=350 \mathrm{MPa}$, and the resulting curve is compared to the Winter curve in Fig. 12 (brown line). The agreement is very good over the whole slenderness range up to $\lambda=4.5$ (Fig. 11 suggests the predictions should be treated with caution for $\lambda>\sqrt{20} \approx$ 4.5), although the theoretical approach predicts slightly higher capacities at high slenderness values. The Winter equation is known to become somewhat conservative in this higher slenderness range, although only a future extensive comparison with experimental data can indicate which curve is more accurate.

A closed form expression for the plate capacity can also be derived by again neglecting the terms in $A_{13}^{3}$ and $A_{13}^{2}$ in Eqs. (62-64). Eliminating $A_{11}$ and $A_{13}$ from these equations and using the failure criterion in Eq. (35) eventually results in the following relationship between the plate slenderness $\lambda$ and the plate capacity $\mathrm{P}_{\mathrm{u}}$ :

591

$$
\frac{1}{\lambda^{2}}=0.81 \frac{\mathrm{P}_{\mathrm{u}}}{\mathrm{P}_{\mathrm{y}}}-0.04 \alpha-0.29+0.25 \frac{\frac{3 \mathrm{P}_{\mathrm{u}}}{\mathrm{P}_{\mathrm{y}}}-1}{\sqrt{1+\frac{1}{\alpha}\left(1-\frac{\mathrm{P}_{u}}{\mathrm{P}_{\mathrm{y}}}\right)}-1}+\sqrt{\frac{\mathrm{c}_{3}\left(\frac{\mathrm{P}_{\mathrm{u}}}{\mathrm{P}_{\mathrm{y}}}\right)^{3}+\mathrm{c}_{2}\left(\frac{\mathrm{P}_{\mathrm{u}}}{\mathrm{P}_{\mathrm{y}}}\right)^{2}+\mathrm{c}_{1}\left(\frac{\mathrm{P}_{\mathrm{u}}}{\mathrm{P}_{\mathrm{y}}}\right)+\mathrm{c}_{0}}{\left(\sqrt{1+\frac{1}{\alpha}\left(1-\frac{\mathrm{P}_{u}}{\mathrm{P}_{\mathrm{y}}}\right)}-1\right)^{2}}+\frac{\mathrm{d}_{2}\left(\frac{\mathrm{P}_{\mathrm{u}}}{\mathrm{P}_{\mathrm{y}}}\right)^{2}+\mathrm{d}_{1}\left(\frac{\mathrm{P}_{\mathrm{u}}}{\mathrm{P}_{\mathrm{y}}}\right)+\mathrm{d}_{0}}{\sqrt{1+\frac{1}{\alpha}\left(1-\frac{\mathrm{P}_{\mathrm{u}}}{\mathrm{P}_{\mathrm{y}}}\right)}-1}}
$$

In the above equation the imperfection factor $\alpha$ is given by Eq. (47), while the coefficients $c_{0}-c_{3}$ and $\mathrm{d}_{0}-\mathrm{d}_{2}$ are listed in Table 1.

Eq. (65) is plotted in Fig. 12 (orange line) and is seen to agree almost exactly with the numerical approach (brown line) up to a slenderness of about 3.5 , while leading to slightly lower predictions after that. Unlike the Winter curve, Eq. (65) captures the gradual transition into full yielding. However, Eq. (65) is obviously more cumbersome in its application and specifies the slenderness as a function of the ultimate load, rather than vice versa.

\section{Parametric studies}

602 Eq. (65) reveals that the plate capacity is a function of only two parameters: the plate slenderness $\lambda$ 603 and the imperfection parameter $\alpha$. According to Eq. (47), $\alpha$ is a function of the yield stress $f_{y}$ of the 
material, the relative imperfection amplitude $A_{0} / L$ and the elastic modulus $E$. This suggests that for steel plates (for which $\mathrm{E}$ is constant independently of the alloy) different Winter-type design curves are needed for different steel grades, as well as for different magnitudes of imperfections. This is at odds with current design standards around the world, which only specify 'the' Winter curve for universal application. A limited parametric study was therefore conducted to study the effects of the yield stress and the imperfection magnitude on the predicted plate capacity.

Fig. 13 plots Eq. (65) for the most common grades of construction steel, ranging from $235 \mathrm{MPa}$ to $960 \mathrm{MPa}$. It is seen that the curves are closely clustered together. A noticeable difference can only be observed in the transition zone towards full yielding, where the design curve for $960 \mathrm{MPa}$ steel predicts approximately $10 \%$ higher values of $\mathrm{P}_{\mathrm{u}} / \mathrm{P}_{\mathrm{y}}$ than the one for $235 \mathrm{MPa}$ steel. The Winter curve appears to form a lower bound to the bundle of curves, closely agreeing with the curve for $f_{y}=235$ MPa over most of its range. This indicates that the Winter equation is an appropriate and safe tool across all steel grades. It is noted that an imperfection amplitude $A_{0}=L / 200$ was assumed for all curves.

Fig. 14 plots Eq. (65) for various imperfection amplitudes $A_{0}$, ranging from $L / 1000$ to $L / 50$. The diagram also shows the predicted capacity of a perfect plate (Eq. 60) and the Winter curve, for comparison. Comparing this graph to Fig. 13, it is seen that the imperfection amplitude has a much more significant effect on the plate capacity, due to the range over which it can realistically be expected to vary, as well as due to its appearance in Eq. (47) as a squared variable. As previously established, the curve with $A_{0}=L / 200$ agrees well with the Winter curve. However, the Winter curve should not be used for stocky plates with expected imperfections exceeding this value. Fig. 14 confirms again that the imperfection sensitivity is most pronounced around $\lambda=1$ and is quite moderate for very slender plates $(\lambda>2.5)$.

\section{Discussion and application}

A number of important and quite general conclusions follow from the above presented theory. A first observation is that the dimensionless capacity $\mathrm{P}_{\mathrm{u}} / \mathrm{P}_{\mathrm{y}}$ of a geometrically perfect plate is only a function of its slenderness $\lambda$, defined by Eq. (6). This fact is demonstrated by Eqs. (36) and (38) - for plates with different boundary conditions - for the case where a single Fourier term is used in the proposed solution. While using two Fourier terms leads to the more complex Eq. (60), it leaves this fundamental conclusion unchanged, which can thus be expected to hold true also for higher order solutions and to be universally valid. It is impossible not to acknowledge the extraordinary contribution of Winter in this regard, who presented his experimental result in the form of $\mathrm{P}_{\mathrm{u}} / \mathrm{P}_{\mathrm{y}} \mathrm{vs}$. $\lambda$ diagram, inspired perhaps by previous work by von Karman et al. (1932) and the theory of columns, 
but without a solid theoretical basis at the time indicating this way forward. Eighty-one years after the first publication of Winter's results this theoretical proof has now been provided. Similarly, in the case of a plate containing an initial geometric imperfection, Eqs. (46) and (65) indicate that the (dimensionless) plate capacity is a function of only two parameters: the plate slenderness $\lambda$ and an imperfection factor $\alpha$, given by Eq. (47). This imperfection factor is a function not only of the amplitude of the geometric imperfection (relative to the width of the plate), but also of the yield stress and the elastic modulus. Eq. (65) makes it possible to quantitatively study the influence of these parameters on the ultimate capacity of the plate, as demonstrated in the previous section. Reflecting on the above paragraph it is impossible to forego a comparison with the theory of Perry and Robertson (Robertson, 1935; Ayrton and Perry, 1886) for (imperfect) columns. Indeed, their theory leads to the same exclusive dependence of the (dimensionless) column capacity on the column slenderness (defined in an analogous way based on the yield stress of the material and the elastic buckling stress) and an imperfection factor. In the Perry-Robertson theory, this imperfection factor is similarly a function of the amplitude of the geometric imperfection (relative to the column length), the yield stress, the elastic modulus and the cross-section geometry (the latter, logically, does not feature in Eq. 47). Incidentally, the Perry-Robertson theory employs the same failure criterion as the one used in this study, namely that the capacity is limited by first yield of the material. As a result, a rather beautiful symmetry is established between the theory of columns and the new theory of plates here presented. It is nearly impossible to overstate the importance of the Perry-Robertson equation, not only for providing theoretical insights into the behaviour of imperfect columns, but also because Eurocode 3 (EN 1993-1-1, CEN 2005) has adopted it as the basis for column design. In the resulting system, the imperfection factor $\alpha$ is generalized to also account for residual stresses, a type of imperfection absent in the theoretical derivation. A group of 'standard' column curves are defined based on a number of discrete values of the imperfection factor, and with the aid of experimental and numerical investigations it was determined which column curve should be used for the design of which type of column. The 'type' of column thereby refers to its cross-sectional shape, yield stress, plate thicknesses and fabrication method (welded or rolled). Based on the theory presented in this paper an entirely analogous approach is now conceivable for the design of plates. The imperfection factor $\alpha$ in Eq. (65) can be generalized to account for 'imperfections' in the general sense, including residual stresses. A number of design 'strength curves', corresponding to different $\alpha$-values, can then be proposed, accompanied by design guidance to be developed in further research. An 
simultaneously buckle locally without exerting any restraint onto each other, thus mimicking single plates with hinged longitudinal edges. The cross-sections were fabricated by welding individual plates together at their junctions. This leads to the introduction of additional residual stresses, as well as increased imperfections (welding distortions), resulting from the heating and cooling process, and it is well known that the Winter curve is not applicable in this case (e.g. Uy, 2001). The data were gathered from research by Bridge and O'Shea (1998), Uy (2001), Huang et al. (2019) and Li et al. (2019) and are summarized in Table 2. The data include specimens with quite a wide range of yield stresses, and while it is appreciated that these differences might to some extent be reflected in the relative magnitude of the residual stresses, Fig. 15 shows quite a clear overall trend. A single design curve was therefore deemed appropriate, similar to the conclusions previously drawn from Fig. 13. It is seen that Eq. (65) with an imperfection factor $\alpha=0.14$ provides a good match to the data. This example illustrates the potential of the new approach.

\section{Concluding remarks}

This research set as its primary objective to establish a link between the von Karman equations, describing the nonlinear post-buckling behaviour of elastic plates, and the practical design of metal plates, governed by a Winter-type equation connecting the plate slenderness to its capacity. To achieve this, the von Karman equations were first simplified into a single equation, while being mindful of preserving the inclusion of the main mechanics which govern the post-buckling behaviour of plates. In particular, the development of superimposed longitudinal membrane tension as a result of plate deflections while the nodal lines of the buckling pattern necessarily remain straight as result of (anti-)symmetry between consecutive buckles was identified as the main mechanism determining the transverse stress distribution in the post-buckling range. The resulting equation was solved using a truncated Fourier series and the results compared to the output of an elastic geometrically nonlinear finite element analysis either with or without the inclusion of an initial imperfection. Using a single Fourier term yielded good agreement for strains up to six times the buckling strain, while this range could be considerably extended to about twenty times the buckling strain when two Fourier terms were included. The latter is believed to be amply sufficient for virtually all practical applications.

In order to arrive at capacity predictions, the theory was wed to von Karman's failure criterion, corresponding to yielding of the effective strips. This allowed a closed form strength equation to be derived, which showed a remarkable agreement with the experimental Winter curve when accounting for typical (equivalent) imperfections. This equation revealed the capacity of an 
imperfect compressed plate to be a sole function of its slenderness and an imperfection factor, spurring comparison with the Perry-Robertson equation for columns, and allowing: 1. a theoretical study of the various factors affecting the plate capacity through the imperfection factor, and 2 . the development of practical design curves for various applications. The latter was illustrated for the case of welded box sections.

\section{Data availability statement}

Some or all data, models, or code that support the findings of this study are available from the corresponding author upon reasonable request.

\section{REFERENCES}

Aalami, B., and Williams, D.G. (1979). Thin Plate Design for In-Plane Loading, Granada, London.

Abaqus (2017). Abaqus software, Simulia (Dassault Systèmes), France.

Assadi-Lamouki, A., and Krauthammer, T. (1989). "An explicit finite difference approach for the Mindlin plate analysis." Computers and Structures, 31 (4), 487-494.

Ayrton, W.E., and Perry, J. (1886). On struts. The Engineer

Basaglia, C., Camotim, D., and Silvestre, N. (2011). “Non-linear GBT formulation for open-section thin-walled members with arbitrary support conditions." Computers \& Structures, 89 (21-22), 1906-1919.

Basu, A.K., and Chapman, J.C. (1966). "Large Deflection Behaviour of Transversely Loaded Rectangular Orthotropic Plates." Proceedings of the Institution of Civil Engineers, 35, 79-110.

Becque, J. (2014). "Local-overall interaction buckling of inelastic columns: A numerical study of the inelastic Van der Neut column." Thin-Walled Structures, 81 (special issue), 101-107.

Bridge, R.Q., and O'Shea, M.D. (1998). “Behaviour of thin-walled box sections with or without internal restraint." Journal of Constructional Steel Research, 47, 73-91.

Brown, J.C., and Harvey, J.M. (1969). "Large deflections of rectangular plates subjected to uniform lateral pressure and compressive edge loading", Journal of Mechanical Engineering Science, 11 (3), 305-317. 
CEN (2005). EN 1993-1-1: Eurocode 3: Design of Steel Structures, Part 1-1: General rules and rules for buildings. European Committee for Standardization, Brussels.

CEN (2006). EN 1993-1-5: Eurocode 3: Design of Steel Structures, Part 1-5: Plated Structural Elements. European Committee for Standardization, Brussels.

Cheung, Y.K. (1976). Finite Strip Method in Structural Analysis, Pergamon Press, New York.

Chia, C.Y. (1980). Nonlinear analysis of plates. McGraw-Hill, New York, NY, USA.

Cox, H. L. (1933). The Buckling of Thin Plates in Compression. British A.R.C. report No. 1554.

Fan, S.C. (1982). Spline finite strip method in structural analysis. PhD Thesis, The University of Hong Kong, Hong Kong.

Föppl, A. 1907. Vorlesungen Über Technische Mechanik, Druck und Verlag von B.G. Teubner.

Graves Smith, T.R. (1969). "The local buckling of box girders under bending stresses." International Journal of the Mechanical Sciences, 11, 603-612.

Graves Smith, T.R., and Sridharan, S. (1978). "A finite strip method for the post-locally buckled analysis of plate structures." International Journal of the Mechanical Sciences, 20(12), 833-842.

Guarracino, F. (2007). “Considerations on the numerical analysis of initial post-buckling behaviour in plates and beams." Thin-Walled Structures, 45, 845-848.

Huang, Z., Li, D., Uy, B., Thai, H.T., and Hou, C. (2019). "Local and post-local buckling of fabricated highstrength steel and composite columns." Journal of Constructional Steel Research, 154, 235-249.

Key, P.W., and Hancock, G.J. (1993). “A Finite Strip Method for the Elastic-Plastic Large Displacement Analysis of Thin-Walled and Cold-Formed Steel Sections." Thin-Wailed Structures, 16, 3-29.

Koiter, W.T., and Pignataro, M. (1976). "A general theory for the interaction between local and overall buckling of stiffened panels." Technical Report WTHD 83. Delft University of Technology, Delft, The Netherlands.

Kwon, Y.B., and Hancock, G.J. (1991). "A Nonlinear Elastic Spline Finite Strip Analysis for Thin-Walled Sections". Thin-Walled Structures, 12, 295-319. 
Lau, S.C., and Hancock, G.J. (1986). "Buckling of thin fiat-walled structures by a spline finite strip method." Thin-Walled Structures, 4, 269-294.

Levy, S. 1942. Bending of rectangular plates with large deflections. NACA Technical Note 846.

Li, D., Huang, Z., Uy, B., Thai, H.T., and Hou, C. (2019). "Slenderness limits for fabricated S960 ultra-highstrength steel and composite columns." Journal of Constructional Steel Research, 159, 109-121.

785

Marguerre, K. (1937). “Die mittragende Breite der gedrückten Platte.” Luftfahrtforschung, Vol. 14, No. 3, 121128. (Also available as: The apparent width of the plate in compression. NACA Technical Memorandum No. 833).

Marguerre, K., and Trefftz, E. (1937). “Über die Tragfähigkeit eines längsbelasteten Plattenstreifens nach Überschreiten der Beullast." Zeitschrift für Angewandte Mathematik und Mechanik, Vol. 17, 85.

Marguerre, K. (1939). "Zur Theorie der Gekrümten Platte Grosser Formänderung.”, Proc., Fifth International Congress on Applied Mechanics, Cambridge, Massachusetts, J. Wiley and Sons, 93-101.

Mayers, J., and Budiansky, B. (1955). Analysis of behavior of simply supported flat plates compressed beyond the buckling load into the plastic range. NACA Technical Note 3368, Washington, USA.

Microsoft (2017). Microsoft Excel, Redmond, Washington, USA.

Nedelcu, M. (2020). "Semi-analytical solutions for the uniformly compressed simply supported plate with large deflections." International Journal of Structural Stability and Dynamics, 20(9).

Okada, H., Oshima, K., and Fukumoto, Y. (1979). “Compressive strength of long rectangular plates under hydrostatic pressure", J. Soc. Naval Arch. (Japan) 146 (1) , 270-280.

Plank, R.J., and Wittrick, W.H. (1974). "Buckling under Combined Loading of Thin, Flat-Walled Structures by a Complex Finite Strip Method." International Journal for Numerical Methods in Engineering, 8 (2), 323339.

Przemieniecki, J.S. (1973), “Finite Element Structural Analysis of Local Instability.” AIAA, 11(1), 33-39.

Reddy, J.N., and Gera, R. (1979). “An improved finite-difference analysis of bending of thin rectangular elastic plates." Computers and Structures, 10, 431-438. 
Rhodes, J., and Harvey, J.M. (1971). "Plates in Uniaxial Compression with Various Support Conditions at the Unloaded Boundaries.", International Journal of Mathematical Sciences, 13, 787-802.

Robertson, A. (1925). The strength of struts. ICE Selected Engineering Papers, Paper 28, ICE, London.

Ruggerini, A.W., Madeo, A., Goncalves, R., Camotim, D., Ubertini, F., and de Miranda, S. (2019). "GBT postbuckling analysis based on the Implicit Corotational Method." International Journal of Solids and Structures, 163, 40-60.

Shen, H.S. (1989). "Postbuckling behavior of rectangular plates under combined loading." Thin-Walled Structures, 8(3), 203-216.

Timoshenko, S.P., and Gere, J.M. (1961). Theory of Elastic Stability, $2^{\text {nd }}$ edition, McGraw-Hill, New York.

Turvey, G.J., and Der Avanassian, N.G.V. (1986). “Elastic large deflection of circular plates using graded finitedifferences." Computers and Structures, 23 (6), 763-774.

Ueda, Y., Rashed, M.H., and Paik, J.K. (1987). "An incremental Galerkin method for plates and stiffened plates", Computers and Structures, 27 (1), 147-156.

Uy, B. (2001). "Local and postlocal buckling of fabricated steel and composite cross sections." Journal of Mathematischen Wissenschaften, Druck und Verlag von B.G. Teubner, 311-385. Applied Mechanics Transactions, 54(5), 53-70. 
854 Walker, A.C. (1969). "Post-buckling behaviour of simply-supported square plates." Aeronautical Quarterly, 20(3), 203.

856

Winter, G. (1940). "Strength Distribution in and Equivalent Width of Flanges of Wide, Thin-Walled Steel Beams." NACA Technical Note 784.

859

860

Winter, G. 1970. Commentary on the 1968 Edition of the Specification for the Design of Cold-Formed Steel 861 Structural Members, American Iron and Steel Institute, New York, USA.

862

863

Yamaki, N. (1959). “Post-Buckling Behaviour of Rectangular Plates with Small Initial Curvature Loaded in Edge 864 Compression." Journal of Applied Mechanics, 26, 407-414.

865

866

867 
Table 1. Coefficients in Eq. (65)

\begin{tabular}{|l|l|}
\hline$c_{3}$ & $-0.506 / \alpha$ \\
\hline$c_{2}$ & $0.518+0.858 / \alpha$ \\
\hline$c_{1}$ & $0.016 \alpha-0.330-0.428 / \alpha$ \\
\hline$c_{0}$ & $-0.014 \alpha^{2}-0.014 \alpha+0.022+0.076 / \alpha$ \\
\hline
\end{tabular}

\begin{tabular}{|l|l|}
\hline$d_{2}$ & 0.053 \\
\hline$d_{1}$ & $-0.028 \alpha-0.019$ \\
\hline$d_{0}$ & $0.787 \alpha^{2}-0.013 \alpha-0.014$ \\
\hline
\end{tabular}

869

870

871

872

Table 2. Data gathered related to local buckling of welded box sections

\begin{tabular}{|c|c|c|c|c|}
\hline Source & $\begin{array}{c}\text { Number of data } \\
\text { points }\end{array}$ & $\begin{array}{c}\text { Nominal } \\
\text { thickness }(\mathbf{m m})\end{array}$ & $\begin{array}{c}\text { Yield stress } \\
\text { (MPa) }\end{array}$ & b/t range* \\
\hline Bridge and O'Shea & 6 & 2 & 282 & $37-131$ \\
\hline Uy & 4 & 3 & 265 & $120-180$ \\
\hline Huang et al. & 4 & 5 & 740 & $18-48$ \\
\hline Li et al. & 4 & 5 & 980 & $18-48$ \\
\hline
\end{tabular}

873

$*_{b}=$ width of the plate; $t=$ thickness

874 
877 Figure 1: Plate boundary conditions for: (a) Case A, and (b) Case B

878 Figure 2: Effective width concept

879 Figure 3: Deformed longitudinal fibre

$880 \quad$ Figure 4: Plate with initial imperfection $\mathrm{w}_{0}$

881 Figure 5: Stress contours of $\sigma_{x}, \tau_{x y}$ and $\sigma_{y}$ obtained from FE analysis for a plate with Case A boundary

882 conditions

883 Figure 6: a. Load vs. axial shortening; b. Load vs. deflection at the centre of the plate

884 Figure 7: Comparison of theoretical predictions with Winter curve

885 Figure 8: Comparison of theoretical load-shortening behaviour of an imperfect plate with FE results

886 Figure 9: Comparison of solution including higher Fourier terms with FE results (perfect plate)

887 Figure 10: Comparison of theoretical design curves with Winter curve

888 Figure 11: Comparison of solution including higher order Fourier terms with FE results (imperfect 889 plate)

890 Figure 12: Comparison of theoretical capacity predictions with Winter curve

891 Figure 13: Strength curves for various steel grades

892 Figure 14: Strength curves for various imperfection amplitudes $A_{0}$

893 Figure 15: Proposed local buckling strength curve for welded box section 


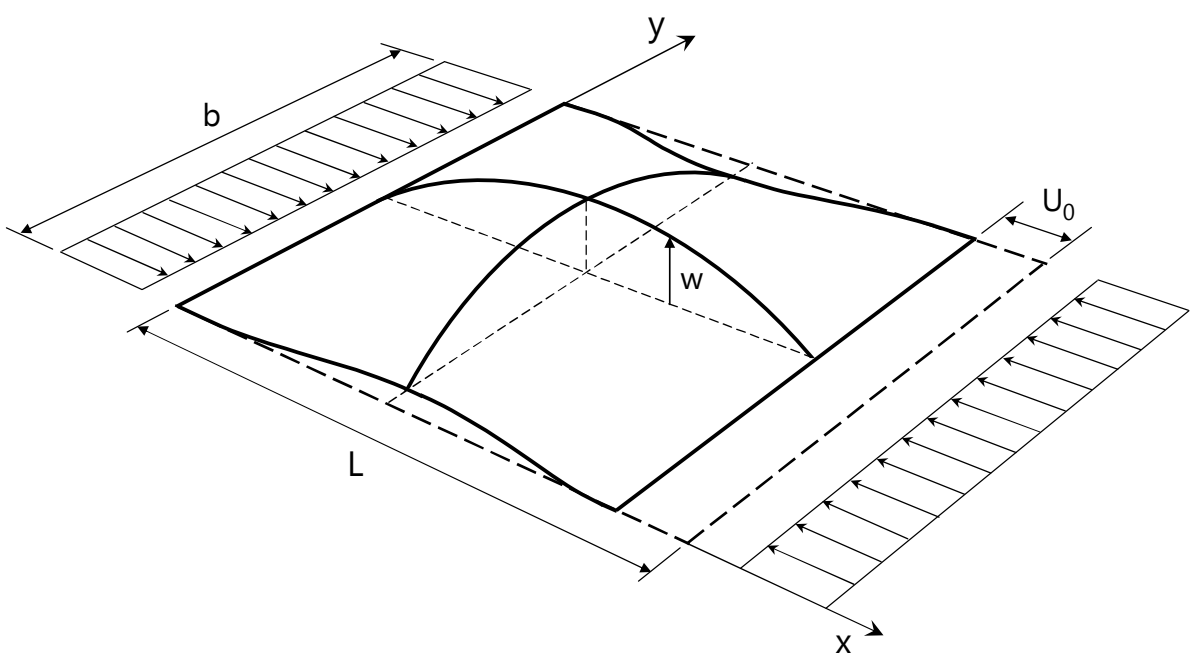

(a)

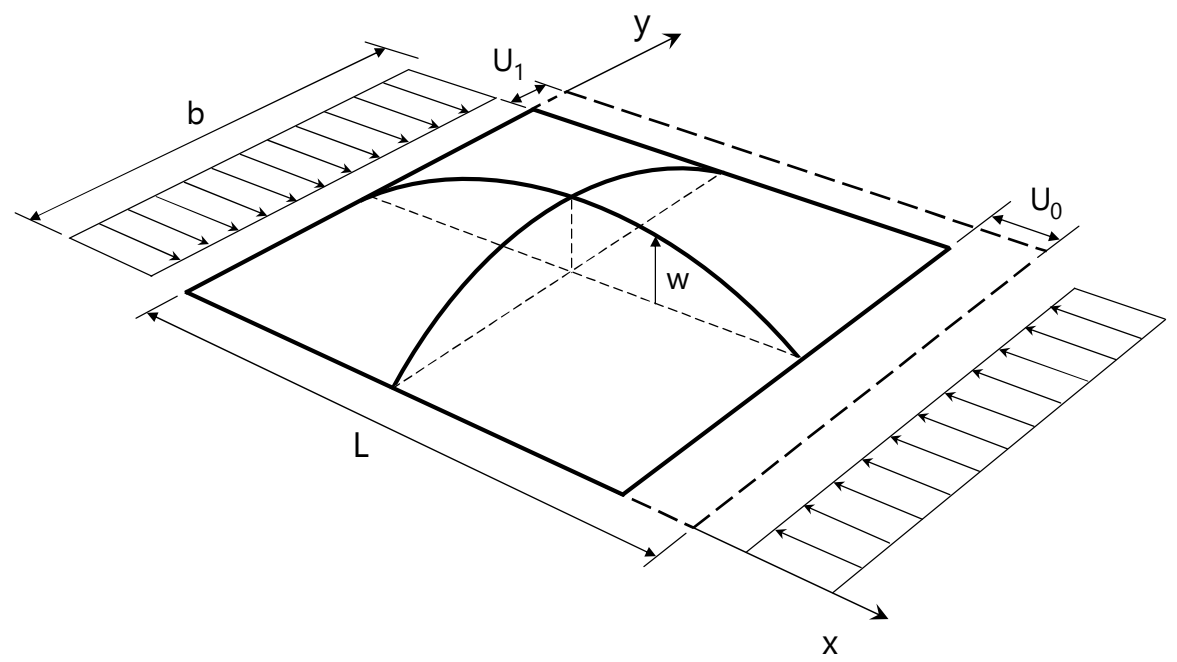

(b)

Figure 1: Plate boundary conditions for: (a) Case A, and (b) Case B 


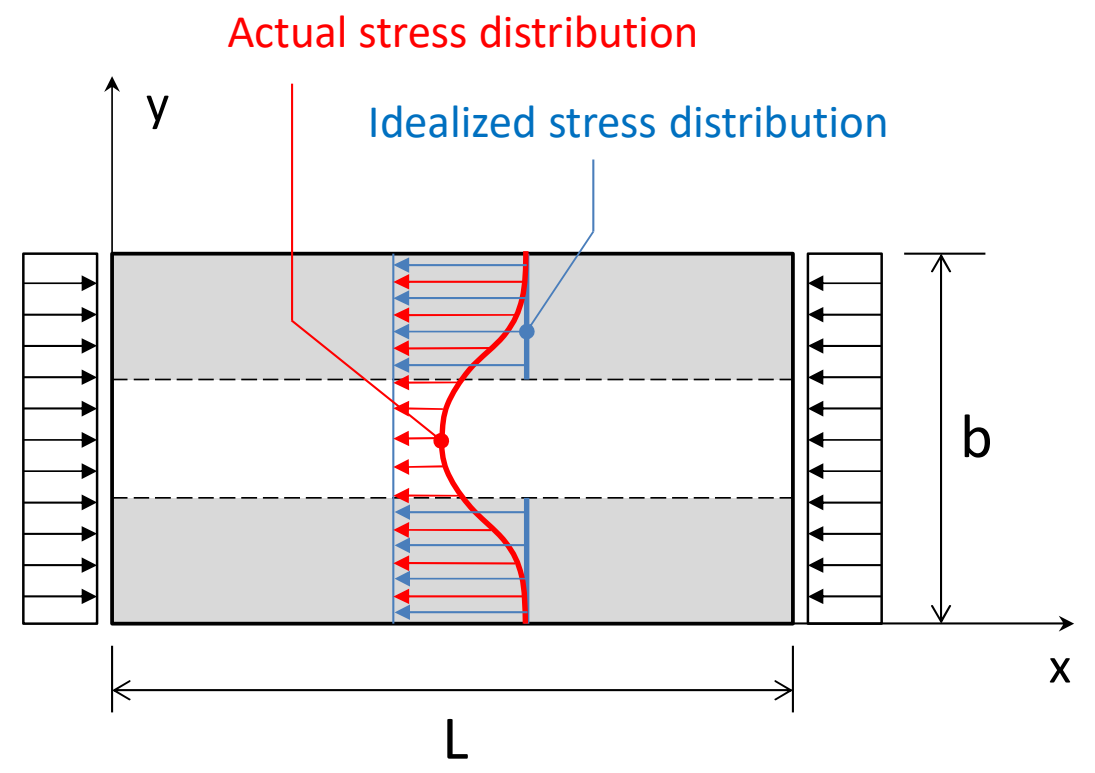

Figure 2: Effective width concept 


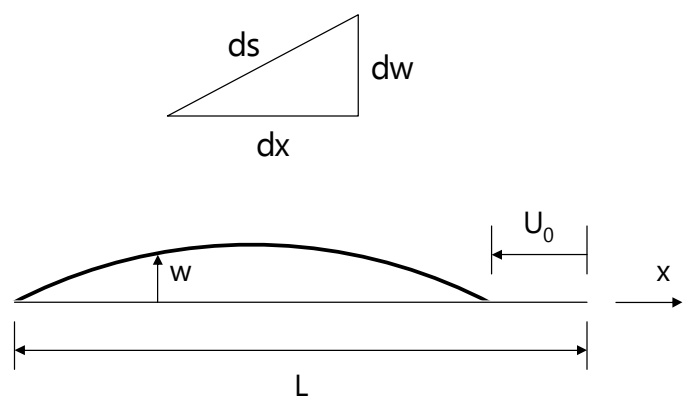

Figure 3: Deformed longitudinal fibre 


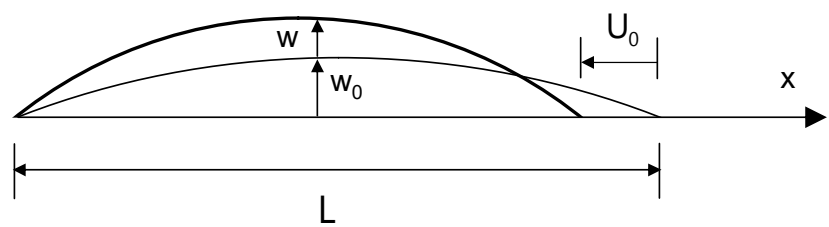

Figure 4: Plate with initial imperfection $w_{0}$ 


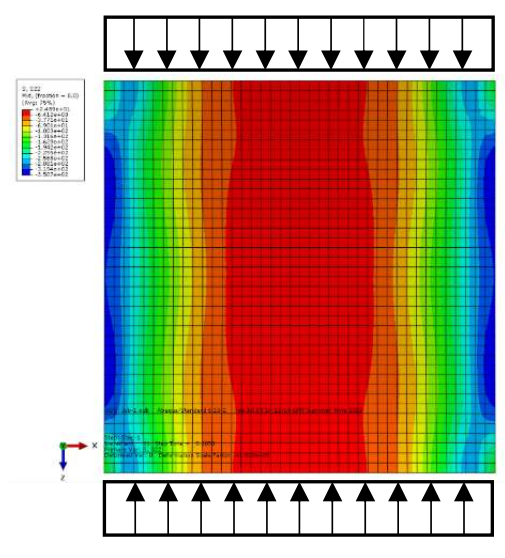

$\sigma_{\mathrm{x}}$
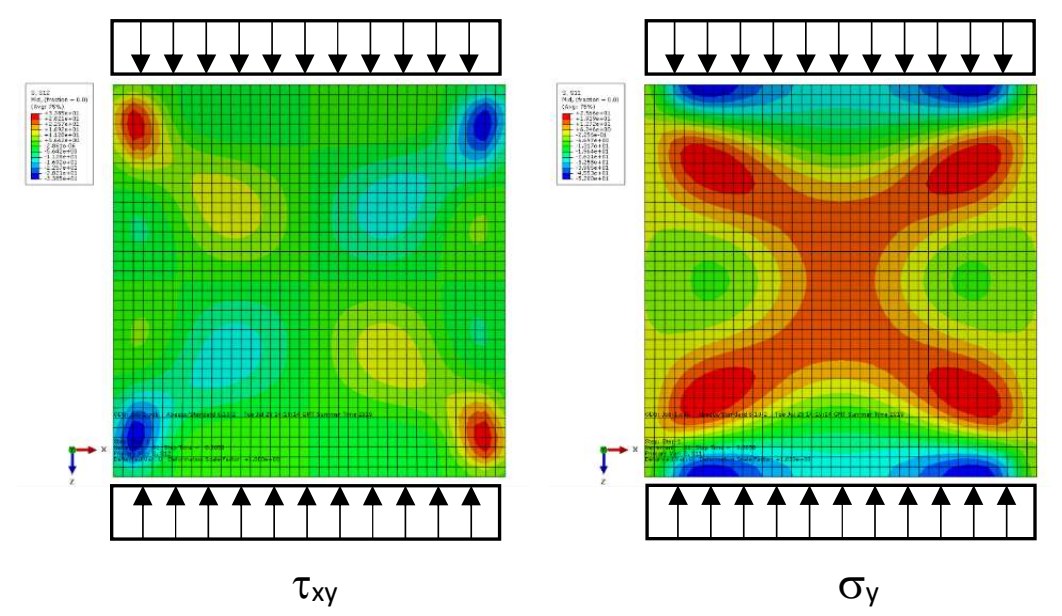

Figure 5: Stress contours of $\sigma_{x}, \tau_{x y}$ and $\sigma_{y}$ obtained from FE analysis for a plate with Case A boundary conditions 

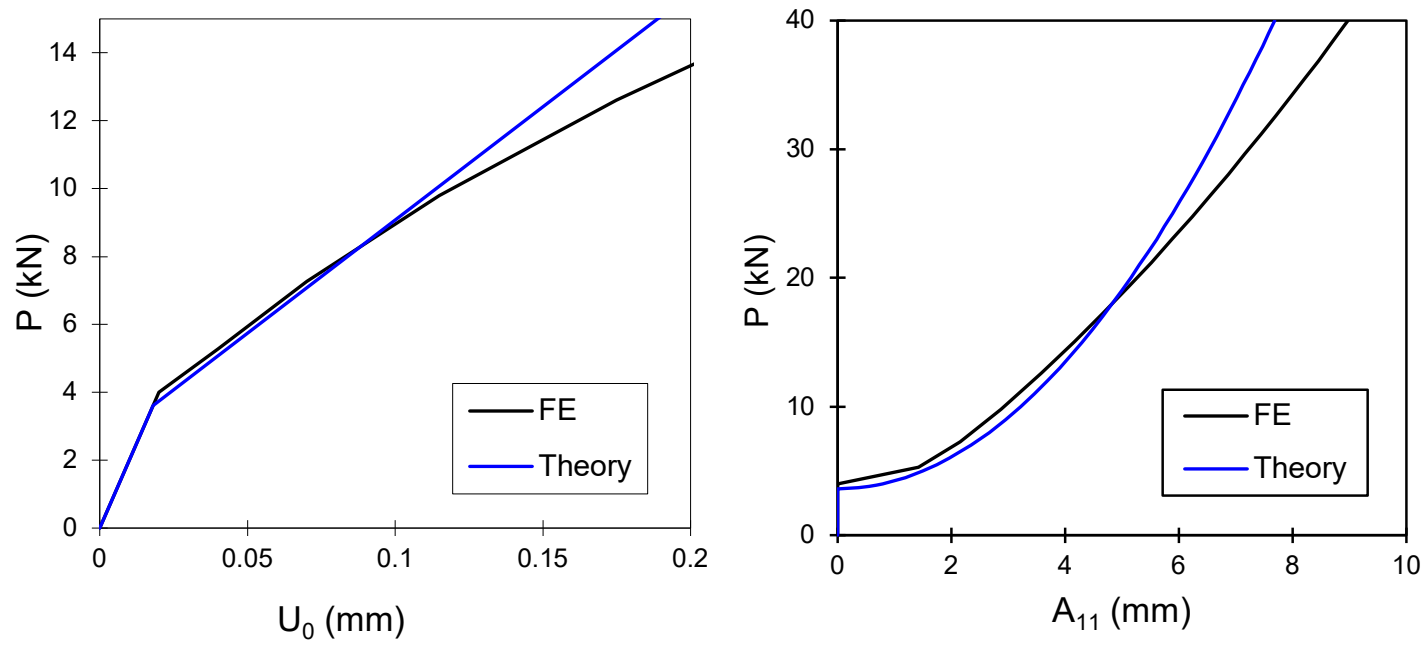

Figure 6: a. Load vs. axial shortening; b. Load vs. deflection at the centre of the plate 


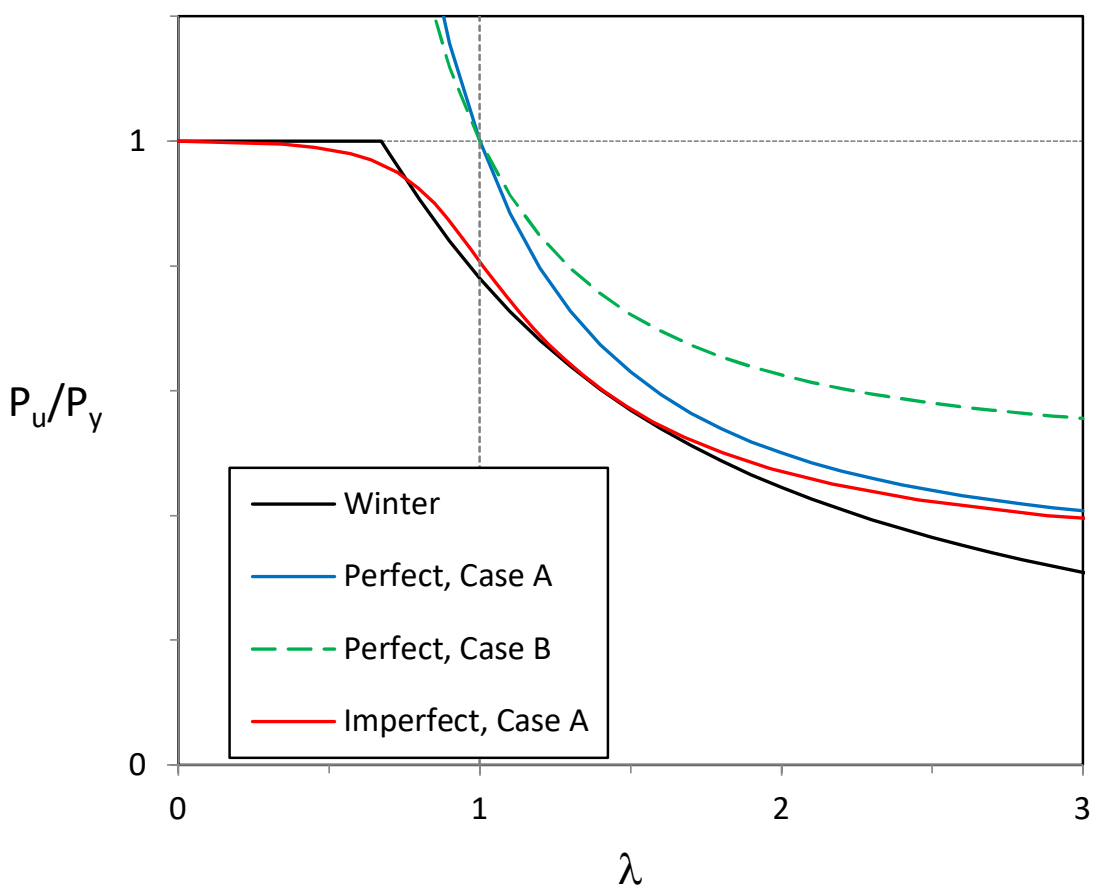

Figure 7. Comparison of theoretical predictions with Winter curve 


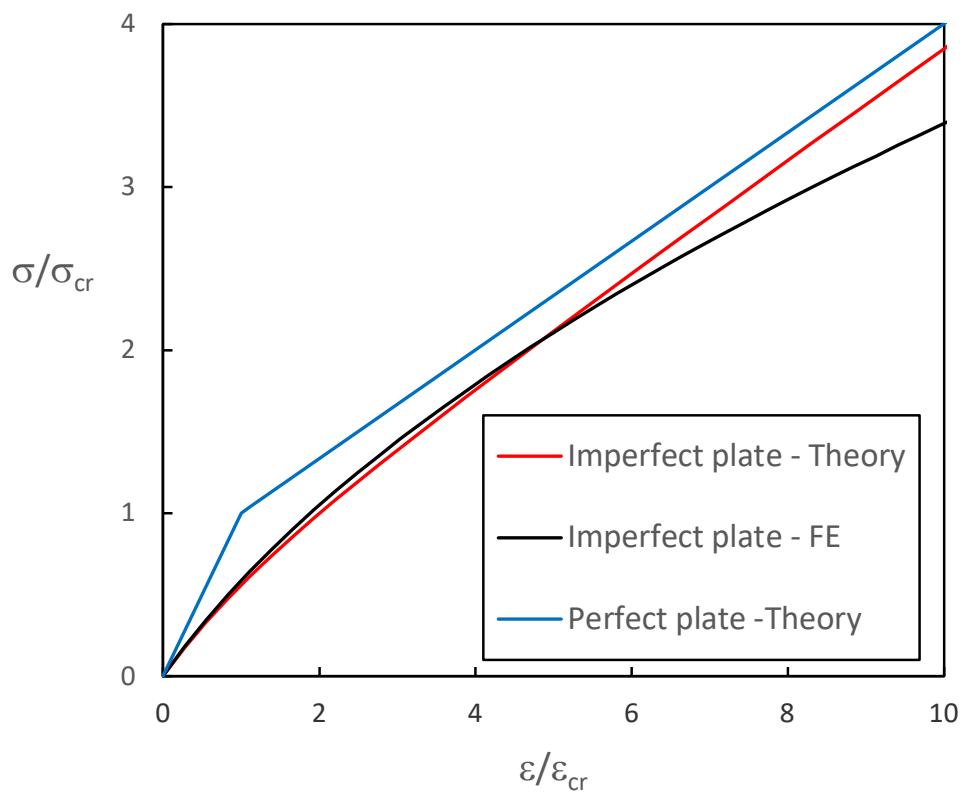

Figure 8. Comparison of theoretical load-shortening behaviour of an imperfect plate with FE results 


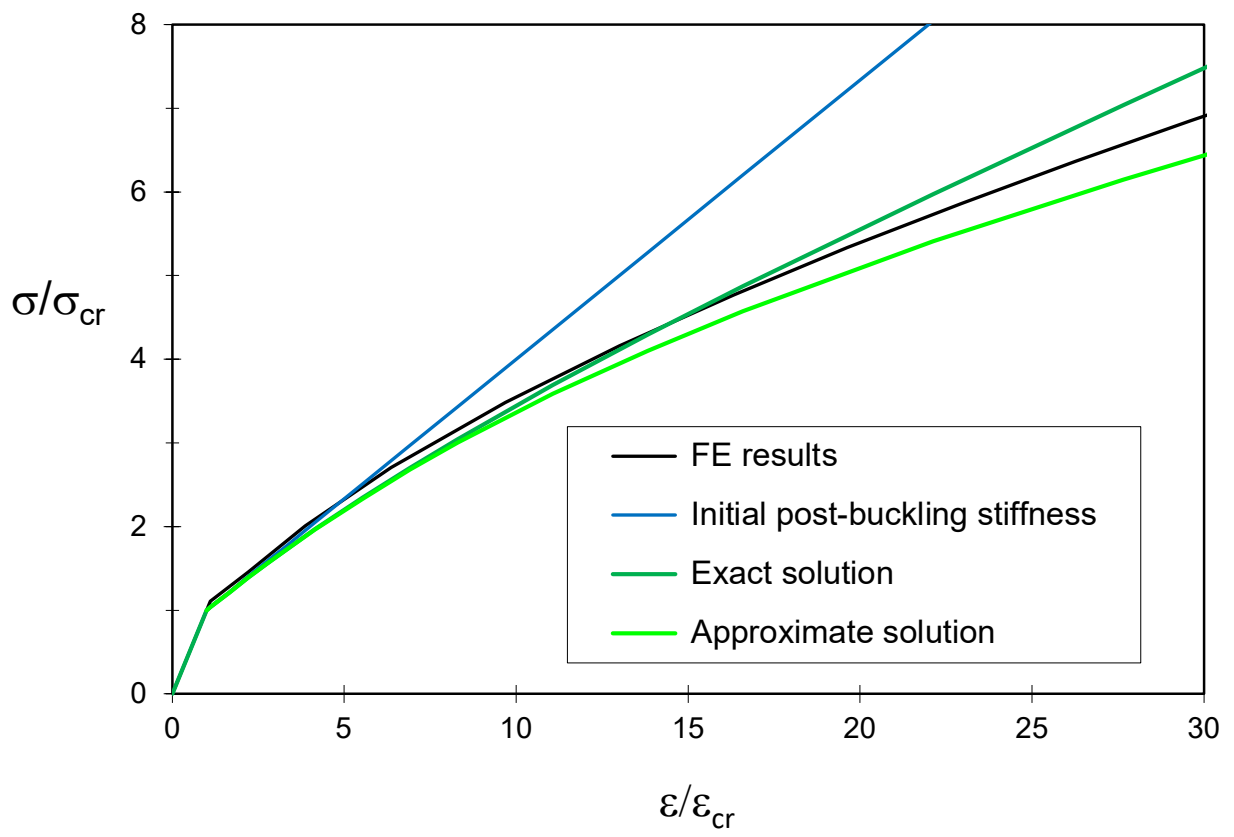

Figure 9. Comparison of solution including higher Fourier terms with FE results (perfect plate) 


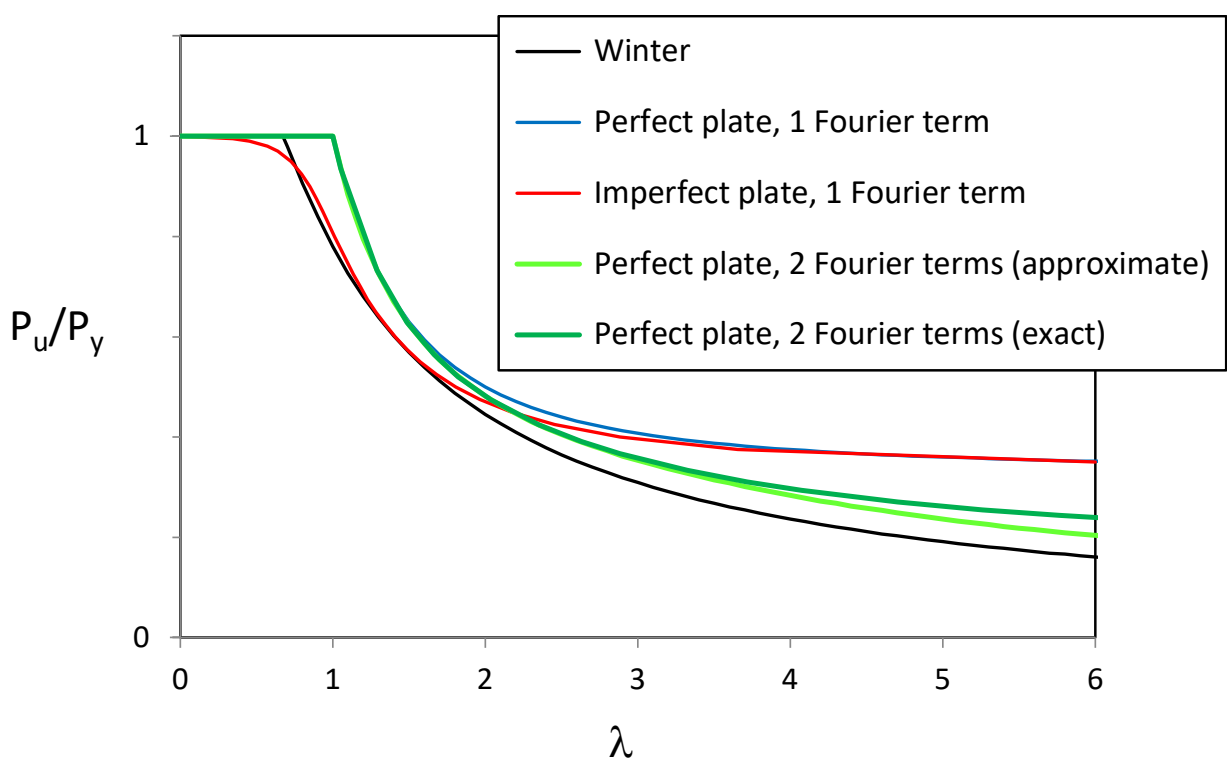

Figure 10. Comparison of theoretical design curves with Winter curve 


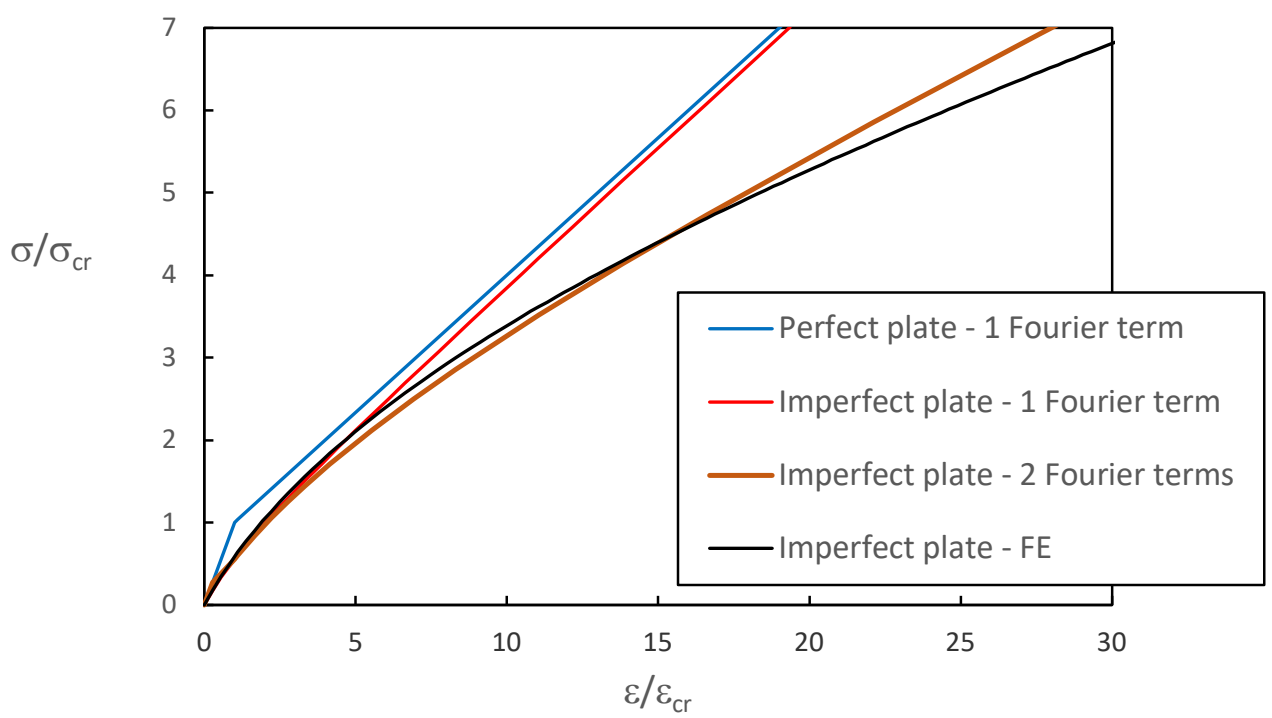

Figure 11: Comparison of solution including higher order Fourier terms with FE results (imperfect plate) 


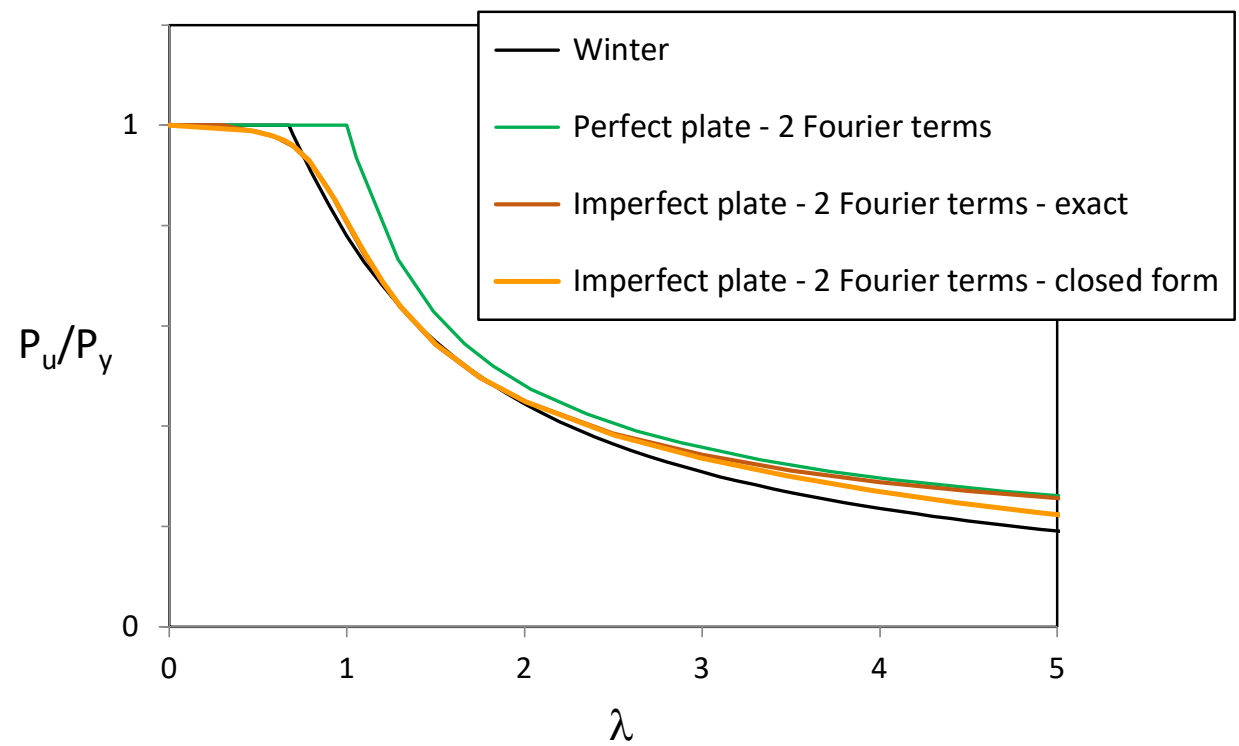

Figure 12: Comparison of theoretical capacity predictions with Winter curve 


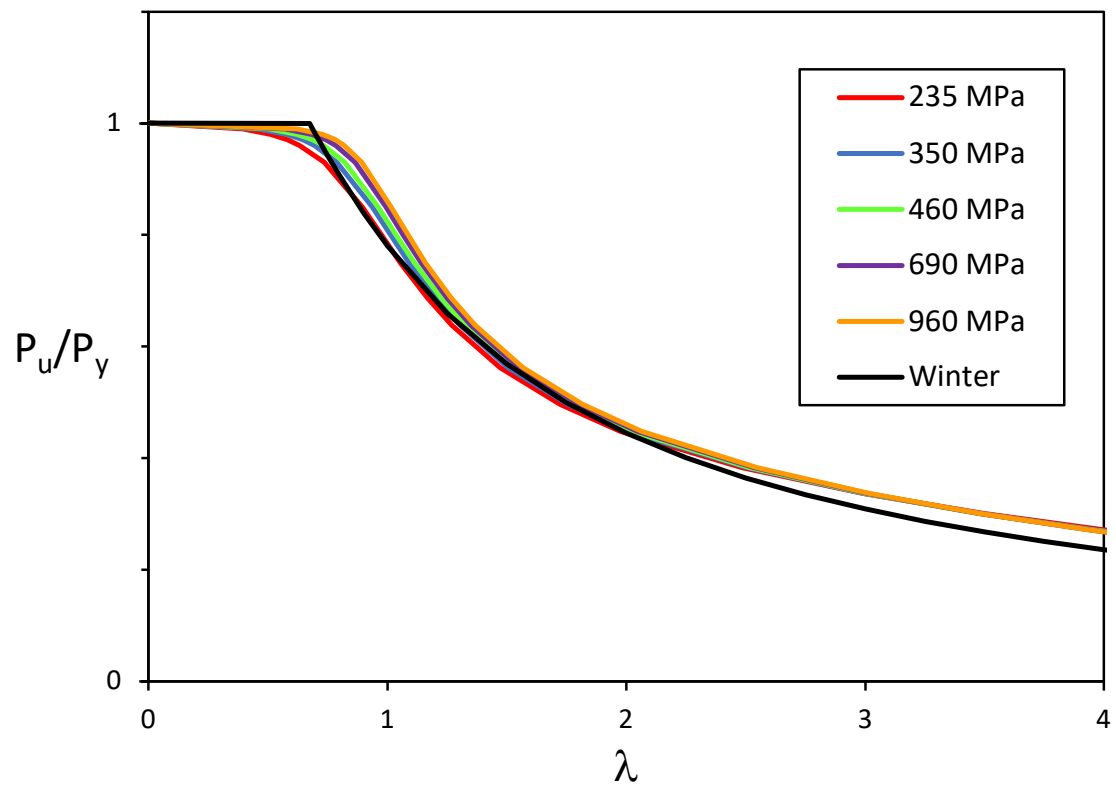

Figure 13: Strength curves for various steel grades 


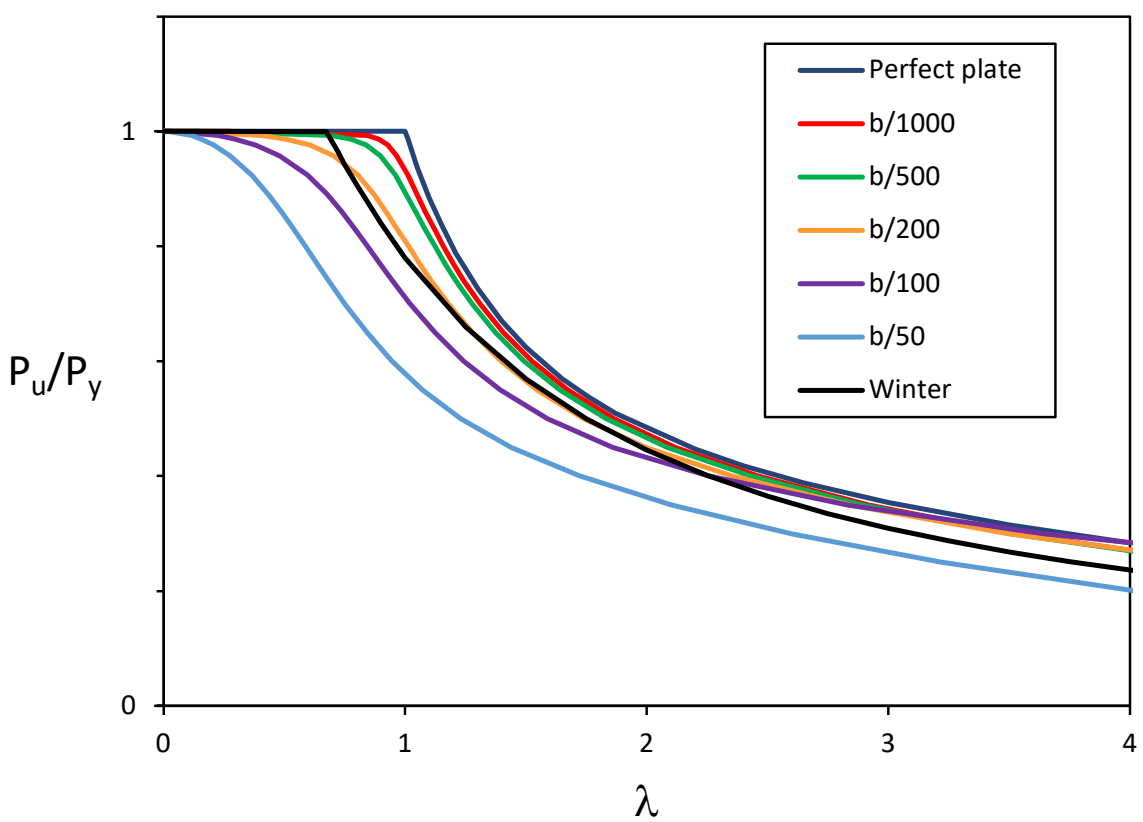

Figure 14: Strength curves for various imperfection amplitudes $A_{0}$ 


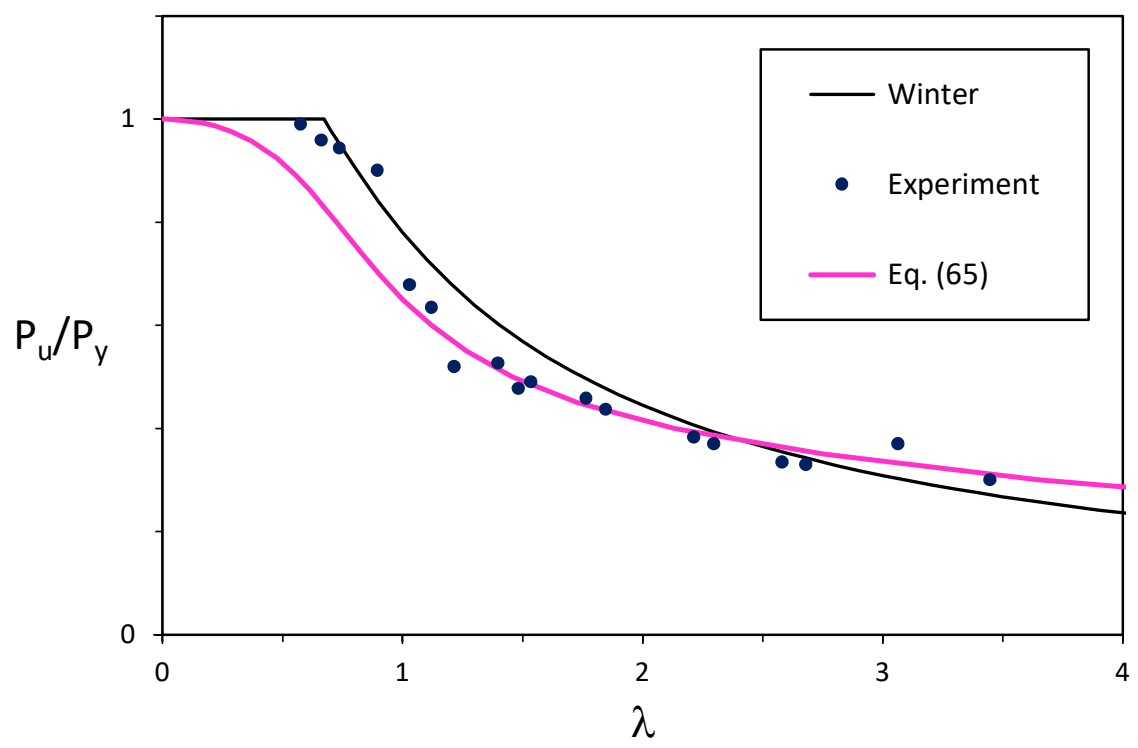

Figure 15: Proposed local buckling strength curve for welded box section 